\title{
Anabases
}

ANABASES Traditions et réceptions de l'Antiquité

$29 \mid 2019$

Varia

\section{L'Antiquité dans la peinture en France, 1791-1880 : une analyse quantitative à travers les Salons et les Prix de Rome}

Antiquity in French Painting 1791-1880: A Quantitative Vision Through the 'Salon' and the 'Prix de Rome'

\section{Mireille Lacave-Allemand et Michel Lacave}

\section{OpenEdition \\ Journals}

Édition électronique

URL : https://journals.openedition.org/anabases/8546

DOI : $10.4000 /$ anabases.8546

ISSN : 2256-942

Éditeur

E.R.A.S.M.E.

Édition imprimée

Date de publication : 14 avril 2019

Pagination : $37-70$

ISSN : 1774-4296

Référence électronique

Mireille Lacave-Allemand et Michel Lacave, «L'Antiquité dans la peinture en France, 1791-1880 : une analyse quantitative à travers les Salons et les Prix de Rome », Anabases [En ligne], 29 | 2019, mis en ligne le 14 avril 2021, consulté le 05 novembre 2021. URL : http://journals.openedition.org/anabases/ 8546 ; DOI : https://doi.org/10.4000/anabases.8546 

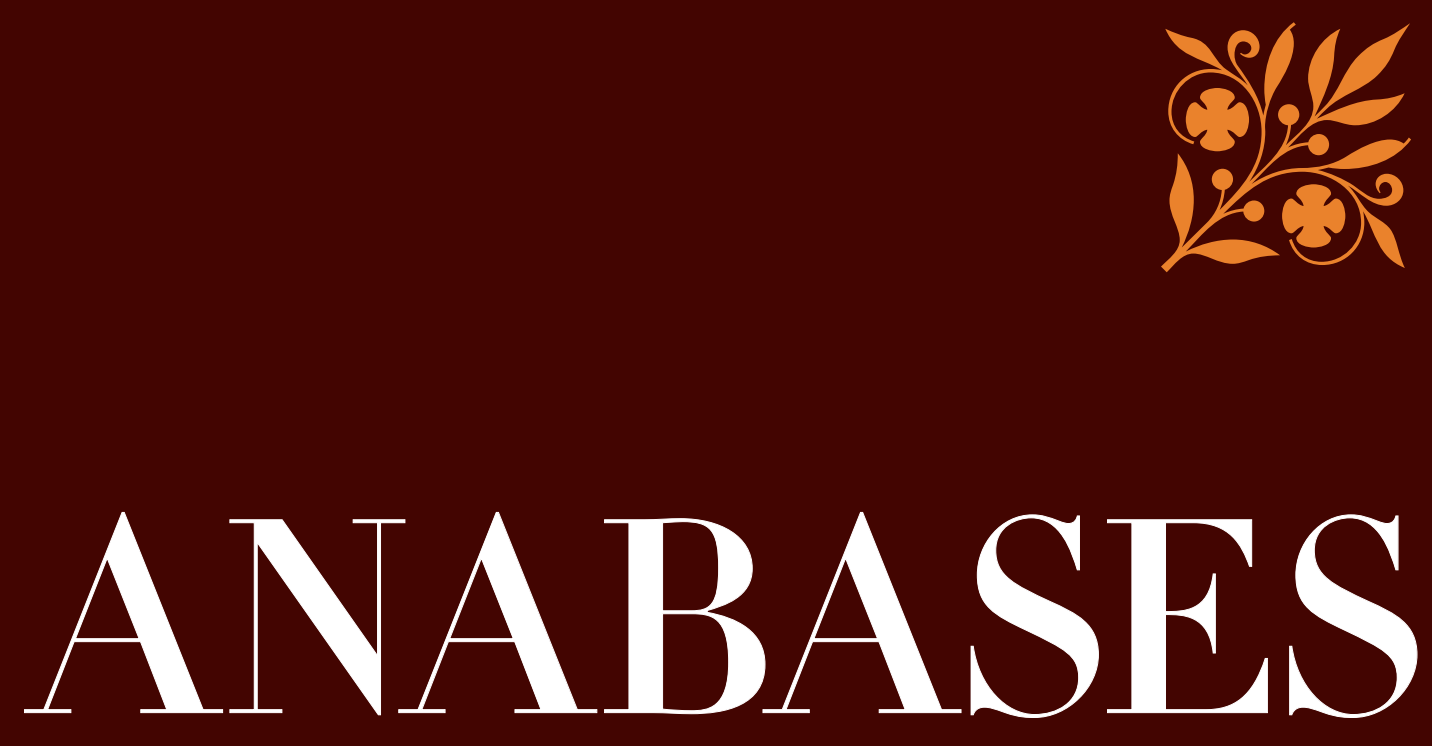

Traditions et Réceptions de l'Antiquité

\section{No29 \\ 2019}

Juliette Ernst Sculptures onctueuses de Meekyoung Shin Théâtre antique et travaux savants dans la Première modernité L'Antiquité dans la peinture (17911880) Réception d'Ovide Pierre Grimal 
ANABASES

Traditions et Réceptions de l'Antiquité

Revue de l'équipe de recherche E.R.A.S.M.E.

Université Toulouse-Jean Jaurès (UT2J)

Anabases dispose d'un Comité de lecture international. Chaque article envoyé à la rédaction est soumis, une fois anonymisé, à l'expertise de deux spécialistes qui rendent un rapport écrit. Les deux rapports anonymisés sont transmis à l'auteur qui tient compte des observations en vue de la publication.

\section{Comité SCIEnTIFIQUe}

Germaine Aujac (université Toulouse-Jean Jaurès : histoire de la géographie et des sciences antiques)

Florence Bouchet (université Toulouse-Jean Jaurès : littérature médiévale)

Hinnerk BruHns (CNRS : histoire économique et sociale ancienne et contemporaine)

Paulo Butti de Lima (université de Bari : historiographie et réception de l'Antiquité)

Luciano CANFora (université de Bari : littérature et histoire anciennes, historiographie)

Giovanna Ceserani (Stanford University : histoire intellectuelle et historiographie de la tradition classique)

Temístocles Cezar (université de Porto Alegre : historiographie moderne)

Serafina Сиомо (University of London, Birkbeck College : histoire des mathématiques et des sciences)

Paul Demont (université de Paris Sorbonne : philologie grecque et héritage classique)

Marie-Laurence Desclos (université de Grenoble II : philosophie de l'Antiquité)

Olivier Devillers (université de Bordeaux 3 - Michel-de-Montaigne : littérature et historiographie latines)

Andrea Giardina (Istituto italiano di scienze umane : histoire du monde romain et de ses réceptions)

Ève Gran-Aymerich (aibl : histoire de l'archéologie et des transferts culturels)

François HaRTog (EHEss : historiographie ancienne et moderne)

Geneviève Hoffmann (université de Picardie : histoire des mondes grecs)

Christian JACOB (CNRS/EHEss : histoire comparée et épistémologie des savoirs)

Suzanne Marchand (Louisiana State University : histoire du classicisme et de l'orientalisme)

Wilfried Nippel (Humboldt Universität Berlin : histoire et historiographie de l'Antiquité)

Sylvie Pittia (université de Paris I-Panthéon Sorbonne : histoire et historiographie du monde romain)

Stéphane Ratri (université de Franche-Comté - Besançon : philologie et héritage latin)

Comité de RÉdaction

Jacques Alexandropoulos, Marielle de Béchillon, Corinne Bonnet, Laurent Bricault, Clément Bur,

Philippe Foro, Adeline Grand-Clément, Anne-Hélène Klinger-Dollé, Véronique Krings,

Thibaud Lanfranchi, Claudine Leduc, Pascal Payen, Grégory Reimond, Catherine Valenti

Éditeur RESPonsable

Pascal PAYen

Université Toulouse-Jean Jaurès (UT2J)

SECRÉTARIAT DE RÉDACTION

Anthony Andurand / Clément Bertau-Courbières / Corinne Bonnet / Clément Bur /

Adeline Grand-Clément / Anne-Hélène Kuinger-Dollé / Véronique Krings /

Catherine Valenti (université Toulouse-Jean Jaurès) / Noémie VillacÈQue (université de Reims)

Sites Web

http://plh.univ-tlse2.fr

Revues.org : http://anabases.revues.org

Aвonnement et vente aU numéro

Éditions De Boccard - 4, rue de Lanneau - 75005 Paris

info@deboccard.com - www.deboccard.com

Tél. : 0033/(0)143260037 - Fax : 0033/(0)143548583 




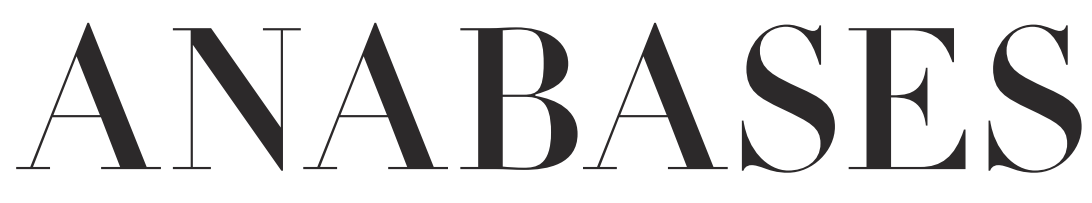

Traditions et Réceptions de l'Antiquité

$$
\begin{aligned}
& N \circ 29 \\
& 2019
\end{aligned}
$$

\section{E.R.A.S.M.E.}

Université Toulouse - Jean Jaurès 



\section{Sommaire}

$\mathrm{N}^{\circ} 29-2019$

\section{Historiographie et identités culturelles}

Ilse Hilbold

Les archives d'une bibliographe des sciences de l'Antiquité :

Juliette Ernst et la fabrique des relations internationales . . . . . . . . . I I3

Vivien LONGHI

La crise, une notion politique héritée des Grecs ? . . . . . . . . . . . 2I

Mireille Lacave-Allemand et Michel Lacave,

L’Antiquité dans la peinture en France, I79I-I880 :

une analyse quantitative à travers les Salons et les Prix de Rome . . . . . 37

Tiphaine Besnard

Du Weathering Project aux autoportraits en Venus :

Les sculptures onctueuses et savonneuses de Meekyoung Shin . . . . . 7 I

\section{Traditions du patrimoine antique}

Dossier dirigé par Pascale Paré-Rey et Malika Bastin-Hammou,

“La réception du théâtre antique dans les travaux savants de l’Europe

de la Première modernité »

Malika Bastin-Hammou et Pascale Paré-Rey

“ La réception du théâtre antique dans les travaux savants

de l'Europe de la Première modernité » . . . . . . . . . . . . . . . . 89

Kevin Bovier

Rétablir la métrique de Térence au $\mathrm{XvI}^{\mathrm{e}}$ siècle :

le cas du Iudicium de Glaréan (1540) . . . . . . . . . . . . . . . . . . . . . . 93 
Brice Denoyer

L'héritage de la métrique antique

dans l'alexandrin français au xvie siècle . . . . . . . . . . . . . IO7

Giovanna Di Martino

Vittorio Alfieri's tormented relationship with Aeschylus:

Agamennone between Tradition and Innovation . . . . . . . . . . . . . . . I2I

Marco Duranti

La condanna del prologo diegetico euripideo dagli scoli antichi

ai trattati del Cinquecento . . . . . . . . . . . . . . .

Rosario López Gregoris

L'influence de l' Arte nuevo de hacer comedias de Lope de Vega

dans l'usage des modèles classiques latins en Espagne

pendant le Siècle d'or et le Baroque » . . . . . . . . . . . . . . . . I49

Cressida Ryan

Sophoclean scholarship as a tool

to interpret eighteenth-century England . . . . . . . . . . . . . . г 6 I

Záviš ŠumaN

Axiologie critique de La Mesnardière . . . . . . . . . . . . . . . . . . . . I79

\section{Archéologie des savoirs}

Dossier dirigé par Cristina Noacco

“2000 ans déjà... Aspects de la réception d'Ovide » . . . . . . . . . . . I93

\section{La réception d'Ovide au Moyen Âge}

Jean-Marie Fritz et Cristina NoAcco

Lire Ovide au xiI ${ }^{\mathrm{e}}$ siècle : Arnoul d'Orléans

commentateur des Métamorphoses . . . . . . . . . . . . . . . $\quad{ }_{195}$

Franck Coulson

Le mythe de Pythagore dans le commentaire

“Vulgate » des Métamorphoses . . . . . . . . . . . . . . . . . . . . . . 2I

Marylène Possamaï

Comment éditer l'Ovide moralisé :

le problème de la mise en page du manuscrit Rouen Bm O.4 . . . . . . . 225

Anneliese Pollock Renck

Les Hérö̈des à la fin du Moyen Âge : pour une définition élargie de l'acte traducteur . . . . . . . . . . . . . . . . . . 239 
II. La réception d'Ovide à l'époque moderne

Fátima Díez Platas et Patricia Meilán Jácome

Le poète dans son œuvre. Ovide dans les images des Fasti

et des Tristia entre les Xv et $\mathrm{xvI}^{\mathrm{e}}$ siècles . . . . . . . . . . . . . . . . . 255

Ana Paula Rebelo Correia

Les représentations des Métamorphoses d'Ovide

dans les azulejos portugais. Influence des modèles gravés français . . . . 269

Sarah ReY

Figures d'Orphée au cinéma . . . . . . . . . . . . . . . . . . . 277

\section{Actualités et débats}

Marine LE BAIL

La modernité littéraire serait-elle affaire d'Antiquité(s) ?

Euvres \& Critiques: La contribution de l'archéologie à la genèse

de la littérature moderne, XLII, I, René Sternke dir., 20I7, 338 p. . . . . . . 2 29I

\section{Lire, relire la bibliothèque des sciences de l'Antiquité}

Éric Morvillez

“Les Horti Tauriani de Pierre Grimal

ou les prémices des Jardins romains » . . . . . . . . . . . . . . . . 30I

Pierre Grimal

“Les Horti Tauriani. Étude topographique sur la région

de la Porte Majeur ",MEFRA, tome 53, rg36. p. 25o-286 . . . . . . . . . . . 3 3i3

\section{L'atelier de l'histoire : chantiers historiographiques}

L'Antiquité au musée (coordonné par Adeline Grand-Clément) (6)

Aurélie Rodes, Catherine Valenti

Les Gaulois au musée . . . . . . . . . . . . . . . . . . . .

355

L'Atelier des doctorants (coordonné par Adeline Grand-Clément) (16)

Andrea Avalli

La question étrusque dans l'Italie fasciste $\ldots \ldots \ldots$. . . . . . . 360 
Droit et réception de l'Antiquité

(coordonné par Marielle de Béchillon et Hélène Ménard) (6)

Entre Clio et Thémis. Entretien avec Dario Mantovani, réalisé par

Hélène Ménard (Maître de Conférences d'Histoire romaine, à l'Université

Paul Valéry - Montpellier III), le 22 juin 20I8, à l'occasion de la parution

aux Belles Lettres du livre Les juristes écrivains de la Rome antique.

Les ouvres des juristes comme littérature (juin 20ı8) et de la création

de la chaire “ Droit, culture et société de la Rome antique »

au Collège de France $\left(\mathrm{I}^{\mathrm{er}}\right.$ novembre $\left.20 \mathrm{I} 8\right) \ldots$. . . . . . . . . . . . .

\section{Comptes rendus}

Philippe Borgeaud et Sara Petrella

Le singe de l'autre.

Du sauvage américain à l'histoire comparée des religions (A. Guedon) . . $\quad 37 \mathrm{I}$

Roberta Casagrande-Kim, Samuel Thrope et Raquel Ukeles (éd.)

Romance and reason. Islamic transformations of the classical past

(Cl. Bertau-Courbières) . . . . . . . . . . . . . . . . . . . . .

Hinnerk BruHns

Max Webers historische Sozialökonomie.

L'économie de Max Weber entre histoire et sociologie (Th. Lanfranchi) . . 374

Andrea Cozzo

Riso e sorriso, e altre saggi sulla nonviolenza nella Grecia antica,

(Fr. Pr. Barone) . . . . . . . . . . . . . . . . . . . 377

Franz Cumont

Manichéisme (St. Ratti) . . . . . . . . . . . . . . . 378

Emmanuelle HÉnin et Valérie NAAs (dir.)

Le mythe de l'art antique (Cl. Evrard) . . . . . . . . . . . . . . . . . 380

Jacques Jouanna, Henri Lavagne, Alain Pasquier,

Véronique SchiLtz et Michel Zink (éd.)

Au-delà du Savoir : Les Reinach et le Monde des Arts (G. Hoffmann) . . . .

382

Mario Liverani

Imagining Babylon: The Modern Story of an Ancient City (C.Bonnet) . . . 386

Françoise-Hélène Massa-Pairault, Claude Pouzadoux (Dir.)

Géants et Gigantomachie entre Orient et Occident (C.Giovénal) . . . . . . .

Scott McGill, Joseph Pucci (éd.)

Classics renewed. Reception and Innovation in the Latin Poetry

ofLate Antiquity (S. Clément-Tarantino) . . . . . . . . . . . . . . . . . . . 
Maxwell T. PAule

Canidia, Rome's First Witch (C. Landrea) . . . . . . . . . . . . . . . . . . . 39г

Jessica Priestley, Vasiliki Zali (éd.)

Brill's Companion to the Reception of Herodotus in Antiquity

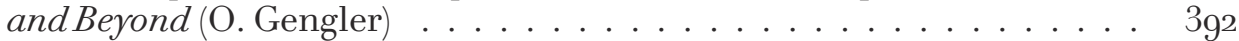

Salvatore QuAsimodo

La Lyre grecque $(\mathrm{M}$. Bianco) . . . . . . . . . . . . . . . . . . 395

Brett M. Rogers, Benjamin Eldon Stevens (éd.)

Classical Traditions in Modern Fantasy (M. Scapin) . . . . . . . . . . . . . 397

Maria Teresa Schettino et Céline UrLacher-Becht (dir.)

Ipse dixit. L'autorité intellectuelle des Anciens : affirmation,

appropriations, détournements (C. Psilakis) . . . . . . . . . . . . . 398

Guy G. Stroumsa

Religions d'Abraham : histoires croisées (D. Lorin) . . . . . . . . . . . . 400

Jean Yvonneau (éd.)

La Muse au long couteau. Critias, de la création littéraire

au terrorisme d'État (G. Hoffmann) . . . . . . . . . . . . . . 405

Résumés . . . . . . . . . . . . . . . . . . . . . 409

Index .............................. 423 



\section{Historiographie et identités culturelles}



Anabases 29 (2019), p. 37-70.

\title{
L'Antiquité dans la peinture en France, 1791-1880: une analyse quantitative à travers les Salons et les Prix de Rome
}

\author{
Mireille Lacave-Allemand \\ Michel LaCAVE
}

D eux moments de réutilisation, réinterprétation, «transposition $»^{1}$ de l'Antiquité grecque et romaine marquent la période 1791-1880 : le néo-classicisme de David dès la fin du xvıI ${ }^{\mathrm{e}}$ siècle, avec en particulier Le serment des Horaces (1785), puis Les Sabines (1796-1799); le courant néo-grec formé dans la seconde moitié des années 1840 dans l'atelier de Charles Gleyre ${ }^{2}$ et illustré notamment par Gérôme avec ses Jeunes grecs faisant combattre des coqs (1846). À propos du premier moment, on peut rappeler que certains élèves de l'atelier de David sont allés jusqu’à former le groupe des “ Primitifs » ou « Barbus » poussant très loin le culte des Grecs ${ }^{3}$. Recherches et études sur ces courants ont donné lieu à une abondante bibliographie ${ }^{4}$. Deux articles récents ont abordé la question de

1 G. Genette, Palimpsestes, Paris 1982, p. 18 et 291.

2 W. Hauptman, Charles Gleyre 1806-1874, Life and Works, Princeton 1996.

3 N. Schlénoff, Ingres, ses sources littéraires, Paris 1956, p. 62.

4 Voir notamment: P. Rosenberg (dir.), F. Cummings, R. Rosenblum, A. Schnapper, De David à Delacroix : La peinture française de 1774 à 1830, 1974. Sur David : A. Schnapper, David: Témoin de son temps, Paris 1980 ; S. LeE , David, Londres 1999. Pour le courant néo-grec : la thèse récente de H. JAGOT, La peinture néo-grecque (1847-1874), Réflexions sur la constitution d'une catégorie stylistique, Paris 2013 ; M. Soler, M. SCAPIN, “ JeanLéon Gérôme au musée d'Orsay, retour à Paris d'un bâtisseur d'images ", Anabases [En ligne], 14 | 2011 (http://anabases.revues.org/2350); La lyre d'ivoire. Henry-Pierre Picou et les Néo-Grecs, Catalogue de l'exposition des Musées de Nantes et Montauban, 
la réception en traitant du tournant néo-grec, l'un consacré à Jean-Léon Gérôme 5 , l'autre au " passé gréco-romain dans la peinture européenne de la seconde moitié du XIx ${ }^{e}$ siècle „6. La naissance et le développement du courant néo-grec ont été mis en relation avec le glissement de la " grande peinture d'histoire » vers les scènes de genre, plus appréciées dans les milieux bourgeois sous la Monarchie de Juillet, un thème lui aussi largement traité7 : “ moins de leçons d'histoire et plus de charme ».

Notre présent propos est volontairement centré sur une analyse quantitative de la réception des thèmes antiques dans la peinture en France entre 1791 et 1880, fondée sur un relevé systématique des sujets et des personnages dans les peintures exposées au Salon à Paris. Nous complèterons cette analyse par une comparaison avec les sujets proposés et les sujets choisis pour le Grand Prix de Rome de Peinture durant la même période.

L'approche quantitative ne nous paraît pas avoir été utilisée jusqu'ici, en tout cas de façon systématique. Sophie Schvalberg a effectué un dépouillement des livrets des Salons de 1840 au début du $\mathrm{xx}^{\mathrm{e}}$ siècle, mais ne livre que des données statistiques partielles 9 . On notera qu'en 1910, dans un article de la Gazette des Beaux-Arts, Léon Rosenthal, esprit original à bien des égards, avait démontré un certain intérêt pour une telle démarche en relevant l'importance du nombre des portraits dans les Salons de 1834, 1841 et 1844, accompagnée de chiffres ${ }^{10}$. Dans sa préface à l'ouvrage de Ph. Grunchec consacré aux concours des Prix de Rome ${ }^{11}$,

Paris 2013. De façon plus générale : L. Rosenthal, Du romantisme au réalisme : essai sur l'évolution de la peinture en France de 1830 à 1848, Paris 1987.

5 M. Soler, M. Scapin, « Jean-Léon Gérôme ».

6 C. CouËLle, “Désirs d'Antique ou comment rêver le passé gréco-romain dans la peinture européenne de la seconde moitié du xix ${ }^{e}$ siècle », Anabases [En ligne], 11 | 2010 (http://anabases.revues.org/760).

7 M.-Cl. Chaudonneret, Le Salon pendant la première moitié du xix siècle : Musée d'art vivant ou marché de l'art?, Villeneuve d'Ascq 2007. HAL Id: halshs-00176804 https:// halshs.archives-ouvertes.fr/halshs-00176804.

8 C. CouËLle, “ Désirs d'Antique », p. 23.

9 S. Schvalberg, Le modèle grec dans l'art français 1815-1914, Rennes 2014, p. 24 et 214 (Orphée), 219 (Daphnis, Chloé), 220 (Nyssia), 223 (Dédale, Icare, Pygmalion). Soulignons que l'auteur ne se limite pas à la peinture.

10 L. Rosenthal, “ Du romantisme au réalisme. Les conditions sociales de la peinture sous la Monarchie de Juillet », Gazette des Beaux-Arts, fév. 1910, p. 93-114. La thèse (française) de Léon Rosenthal, soutenue en 1900, était intitulée La peinture romantique, essai sur l'évolution de la peinture française de 1815 à 1830 (1900, 336 p.).

1 Ph. Grunchec, Les concours des Prix de Rome 1797-1863, préface de Jacques Thuiller, Paris 1986-1989, 2 vol. 
Jacques Thuillier soulignait par ailleurs, à propos des Prix de Rome : « Il est difficile de rencontrer dans l'histoire de l'art la notion de 'série' plus parfaitement réalisée. Et du même coup c'est une autre histoire de l'art qui s'offre ici ... Cette suite de Prix de Rome offre ... une sorte de test annuel qui permet d'obtenir une courbe de caractère quasi-scientifique ». La réflexion vaut à l'évidence tout autant, et sans doute davantage encore, pour le Salon ${ }^{12}$.

La période choisie s'ouvre avec la loi Le Chapelier de 1791 qui permit l'accès au Salon ${ }^{13}$ de tous les artistes, changeant ainsi la donne pour les exposants. À l'autre extrémité, les années 1870 voient l'éclatement progressif du « système des Beaux-Arts » décrit par André Chastel : “Ainsi s'organise un circuit : le Salon où l'on se révèle ; le Luxembourg où l'on est accroché vivant; le Louvre où l'on entre une fois mort. Parallèlement, il y a l'École des Beaux-Arts, le prix de Rome et l'Institut, qui constituent un cursus complet et un cycle sans cesse refermé sur lui-même, puisque les anciens de l'École, devenus membres de l'Institut, viennent y enseigner »14. Les artistes cherchent de plus en plus à s'évader du cadre du Salon organisé par l'Institut ; cette tendance avait certes commencé bien plus tôt, mais la décennie qui s'ouvre au lendemain de la chute du Second Empire en voit une accélération, marquée tant par l'inflation du nombre d'œuvres présentées que les organisateurs tentent de maîtriser par une sélection contestée - que par des manifestations telles que l'exposition des impressionnistes de 1874 chez le photographe $\mathrm{Nadar}^{15}$. Comme le dit Dominique Lobstein dans son ouvrage sur les Salons, les débuts de la Troisième République sont marqués par « une succession de crises », avec une “hypothétique censure » en 1872, un nouveau salon des refusés en 1873, et « la fin d'un temps » avec une « contestation endémique jusqu’à la fin de la décennie » et un “éclectisme jusqu'alors inconnu »(1874-1879) ${ }^{16}$. À partir des années 1880, le Salon n'est plus « l'outil de promotion collective » qu'il était jusqu'alors ${ }^{17}$.

12 Voir C. Caubisens-Lasfargues, “Les Salons de peinture de la Révolution française », L'information d'histoire de l'art, mars-avril 1960, p. 67-73.

13 Voir D. Lobstein, Les Salons au XIXè siècle: Paris, capitale des arts, Paris 2006, p. 17. La loi du 14 juin 1791, dite loi Le Chapelier, a interdit les corporations, et a donc ouvert la reconnaissance de la profession de peintre. La profession était contrôlée par l'Académie de Saint Luc - voir P. Michel, Le commerce du tableau à Paris dans la seconde moitié du XVIII siècle. Acteurs et pratiques, 2007 - et par l'Académie royale de peinture et sculpture.

14 A. Chastel, “ Le paradis des peintres en 1874 », Le Monde, 6 juin 1974, rééd. in : L'Image dans le miroir, Paris 1980, p. 177-178. Voir aussi S. Schvalberg, Le modèle grec, p. 25, qui parle d'un " effet de boucle », y compris pour les nominations au jury du Salon.

15 Voir P. NAHon, Les marchands d'art en France, Paris 1998.

16 D. Lobstein, Les Salons, p. 201, 210 et. 214.

17 Ibid., p. 221. 


\section{Sources et méthodologie}

Les Salons constituent une source très précieuse car ils fournissent une base quantitative extrêmement large. Les sujets des Prix de Rome de Peinture sont évidemment beaucoup moins nombreux et soulèvent peu de problèmes méthodologiques sérieux.

Nous avons retenu ici toutes les peintures représentant des scènes mythologiques ou historiques, des divinités, des héros et personnages mythiques ou historiques (auteurs inclus) de l'Antiquité païenne. Cette sélection inclut toutes les œuvres représentant de façon “ générique » bacchantes, faunes, satyres, nymphes, etc., et l'Amour ${ }^{18}$. Nous avons toutefois exclu les œuvres faisant intervenir divinités et personnages dans un contexte purement allégorique ${ }^{19}$.

Les sources primaires sont constituées par les livrets des Salons, qui ont fait l'objet de deux séquences de réédition : de 1673 à $1799^{20}$, et à partir de $1801^{21}$ (en fac-simile) avec 12 tomes pour la période 1801-1880. Les livrets réédités sont disponibles sur le site Gallica de la Bibliothèque nationale de France. En outre, une base de données a été constituée au Musée d'Orsay à partir des livrets (http:// salons.musee-orsay.fr/22 . Cependant, isoler la catégorie ( peinture », à savoir les tableaux peints à l'huile sur support mobile ${ }^{23}$, dans la base de données peut se révéler assez aléatoire suivant les années, et nous avons dû effectuer de nombreux contrôles dans les livrets pour aboutir à un résultat que nous espérons le plus sûr possible.

Pour les Prix de Rome, les sources sont les procès-verbaux de l'Académie des Beaux-Arts qui retracent les séances au cours desquelles le choix du sujet du prix de Peinture ${ }^{24}$ est effectué, séances qualifiées de séances “ extraordinaires »

18 Dans la sphère littéraire, et non pas picturale, B. DE BAEcque a livré une approche statistique similaire dans La littérature de l'Antiquité dans Les Fleurs du Mal (Mémoire, université de Paris IV - Sorbonne, sous la direction d'André Guyaux, Année 1996-1997).

19 Ainsi par exemple ne retenons-nous pas “Un Amour mettant son carquois, et sous ses pieds les attributs de la Prudence et de la Force »(Salon de 1795, $\mathrm{n}^{\circ} 329$ ).

20 J. J. Guifrrey, Collection des livrets des anciennes expositions ..., années 1673 jusqu'en 1800, Paris 1869-1872.

21 P. Sanchez et X. Seydoux, Les catalogues des Salons, Paris. Les tomes I-XII ont été publiés entre 1999 et 2006.

22 Catégorie « Salon [Paris, avant 1880] ».

23 Nous avons inclus les esquisses de tableaux plus grands, ainsi que celles réalisées pour de futures peintures décoratives.

24 Nous n'avons pas retenu les Prix de Paysage historique, du fait de l'irrégularité des concours sur notre période. 
à compter de 1804. Les procès-verbaux ont fait l'objet de deux séquences d'édition : de 1795-1796 (an IV) à 1810²5; de 1811 à 1854 , et de 1865 à 1869²6. Les lacunes sont comblées, pour la période de 1855 à 1863, par Ph. Grunchec ${ }^{27}$, et pour les années 1871-80, par le dépouillement des procès-verbaux effectuéà l'École des Beaux-Arts effectué par Joëlle de Couessin ${ }^{28}$. À partir de 1807, de façon quasiment régulière ${ }^{29}$, les procès-verbaux des séances extraordinaires indiquent les propositions de sujets qui sont faites par les membres du jury ab initio pour le prix de Peinture, ce qui permet d'enrichir notablement notre approche quantitative des sujets des Prix de Rome.

\section{L'Antiquité au Salon : peintres " antiquisants » et peintures à thèmes antiques}

Soixante salons au total ont été organisés durant notre période. Ils se révèlent assez inégalement répartis dans le temps, car il n'y a que sept salons entre 1812 et 1830 , contre 19 entre 1831 et 1850. Le nombre d'exposants, toutes catégories confondues, a explosé au fil des années passant d'environ 250 en 1791 à 4000 en 1879. Le millier est dépassé en 1831 et se maintient au long de la Monarchie de Juillet. La plus grande partie du Second Empire voit le nombre d'exposants tourner autour de 2000 , et monter jusqu'à près de 3500 en 1870 . Après une chute en 1872-1873, un fort redémarrage se produit dans les premières années de la Troisième République.

Le tableau 1 donne les moyennes décennales de peintres exposants et de notices consacrées à des peintures (ci-après : notices “ peintures ») par salon, afin de tenir compte de l'inégale répartition des salons dans le temps.

25 Procès-verbaux de l’Académie des Beaux-Arts, éd. M. Bonnaire, Paris, 1937-1943, 3 vol.

26 Procès-verbaux de l'Académie des Beaux-Arts, dir. J.-M. Leniaud, Paris, 2001-2015 (volumes I à IX pour la période 1811-1854), 2009 (vol. XII pour la période 1865-1869).

27 Ph. Grunchec, Le Grand Prix de Peinture. Les concours des Prix de Rome de 1797 à 1863, Paris 1983.

28 Dossier ENSBA, Prix de Rome de Peinture 1864-1918. Les originaux se trouvent aux Archives de l'Institut. Nos remerciements vont à Emmanuel Schwartz pour nous avoir grandement facilité l'accès à ce dossier.

Les exceptions sont 1808 et 1810. 


\begin{tabular}{|l|c|c|c|c|c|c|c|c|c|}
\hline \multirow{2}{*}{ Moyennes décennales par salon } & $\mathbf{1 7 9 1 -}$ & $\mathbf{1 8 0 0 -}$ & $\mathbf{1 8 1 1}-$ & $\mathbf{1 8 2 1 -}$ & $\mathbf{1 8 3 1 -}$ & $\mathbf{1 8 4 1 -}$ & $\mathbf{1 8 5 1 -}$ & $\mathbf{1 8 6 1 -}$ & $\mathbf{1 8 7 1 -}$ \\
& $\mathbf{1 7 9 9}$ & $\mathbf{1 8 1 0}$ & $\mathbf{1 8 2 0}$ & $\mathbf{1 8 3 0}$ & $\mathbf{1 8 4 0}$ & $\mathbf{1 8 5 0}$ & $\mathbf{1 8 6 0}$ & $\mathbf{1 8 7 0}$ & $\mathbf{1 8 8 0}$ \\
\hline Peintres exposants & 148 & 277 & 432 & 608 & 949 & 1149 & 1078 & 1517 & 1476 \\
\hline Notices peintures & 415 & 459 & 918 & 1348 & 1715 & 1870 & 2019 & 2155 & 2113 \\
\hline
\end{tabular}

Tableau 1. Peintres exposants et Notices peintures

Moyennes décennales par salon 1791-1880

La moyenne des peintres exposants a été pratiquement multipliée par dix entre la première et la dernière décennie. Le nombre de notices « peintures » a lui aussi connu une augmentation considérable, quoique deux fois moins importante que celle des peintres exposants, avec une multiplication par cinq entre la première et la dernière décennie.

L'inflation du nombre d'exposants ne touche cependant ni le nombre de peintres “ antiquisants » ni le nombre de notices de peintures à thèmes antiques (tableaux 2 et 3 ). Le corpus de peintures à thèmes antiques s'élève à 2421 peintures, soit $2,64 \%$ du total des peintures exposées, avec en moyenne une quarantaine par salon. La peinture à thèmes antiques est donc très minoritaire, même si le corpus est bien loin d'être négligeable. La moyenne de 40 par salon est cependant trompeuse, car la part de peintures à thèmes antiques sur le total des peintures exposées a connu de profonds changements, ainsi que le montre le tableau qui suit (Tableau 2, Graphique 1).

\begin{tabular}{|l|r|r|r|r|r|r|r|r|r|r|}
\hline Décennies & $\begin{array}{c}1791- \\
1799\end{array}$ & $\begin{array}{r}1800- \\
1810\end{array}$ & $\begin{array}{r}1811- \\
1820\end{array}$ & $\begin{array}{r}1821- \\
1830\end{array}$ & $\begin{array}{c}1831- \\
1840\end{array}$ & $\begin{array}{r}1841- \\
1850\end{array}$ & $\begin{array}{r}1851- \\
1860\end{array}$ & $\begin{array}{c}1861- \\
1870\end{array}$ & $\begin{array}{c}1871- \\
1880\end{array}$ & Total \\
\hline $\begin{array}{l}\text { Notices } \\
\text { Peintures }\end{array}$ & 2489 & 3210 & 3674 & 4044 & 15437 & 18703 & 10097 & 19395 & 14790 & 91839 \\
\hline $\begin{array}{l}\text { Notices Peintures } \\
\text { Antiquité }\end{array}$ & 307 & 293 & 254 & 174 & 86 & 228 & 168 & 615 & 296 & $\mathbf{2 4 2 1}$ \\
\hline $\begin{array}{l}\text { \% Peintures } \\
\text { Ant./ Total }\end{array}$ & $12,33 \%$ & $9,13 \%$ & $6,91 \%$ & $4,30 \%$ & $0,56 \%$ & $1,22 \%$ & $1,66 \%$ & $3,17 \%$ & $2,00 \%$ & $\mathbf{2 , 6 4 \%}$ \\
\hline $\begin{array}{l}\text { Moy./ salon } \\
\text { nombre notices } \\
\text { Peint. Antiquité }\end{array}$ & 51 & 42 & 64 & 46 & 29 & 23 & 34 & 68 & 42 & 40 \\
\hline
\end{tabular}

Tableau 2 : Notices peintures à thèmes antiques 1791-1880

30 Du fait de certaines irrégularités dans la tenue des Salons, les décennies 1811-20, 182130, 1851-60 et 1871-80 sont en réalité respectivement des décennies 1812-19, 1822-27, $1852-59$ et $1872-79$.

31 Pour la période 1791-1799, nous avons directement travaillé sur les livrets, car nous avons constaté des écarts significatifs avec les résultats fournis par la base de données

32 d'Orsay.

Idem. 


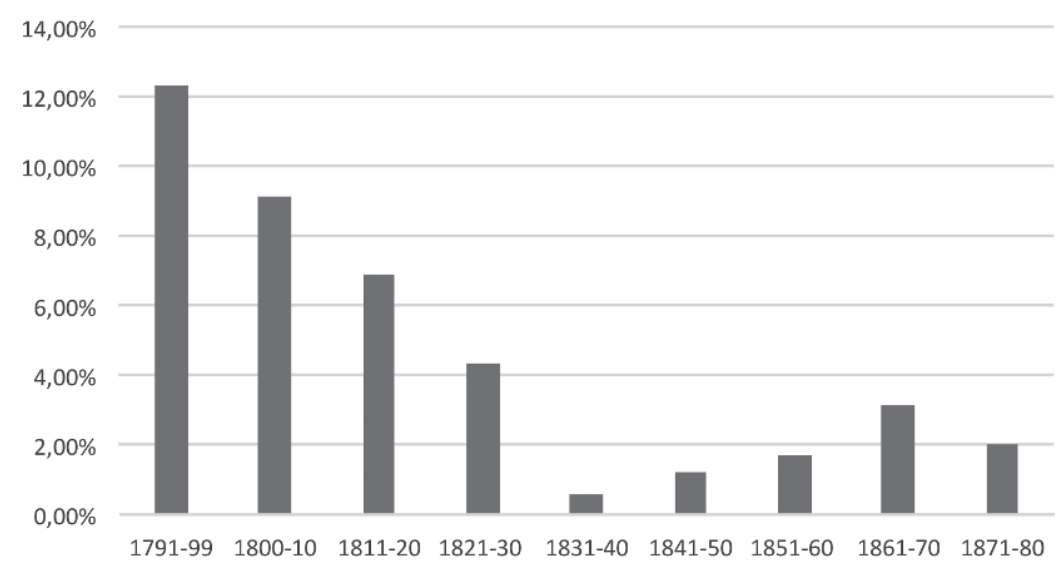

Graphique 1. Pourcentage peintures à thèmes antiques / total peintures 1791-1880

On observe clairement trois phases : une diminution marquée de la part des peintures à thèmes antiques jusqu'au début des années 1830 ; un étiage bas dans les années 1830-1840; une reprise avec une certaine stabilisation à un niveau modeste à partir des années 1850. L'évolution de la moyenne par salon du nombre de peintures à thèmes antiques montre toutefois un maintien en valeur absolue autour de 50 jusqu'en 1830.

Le pourcentage de peintres « antiquisants » sur le total des peintres exposants a connu une évolution à peu près similaire (Tableau 3, Graphique 2).

\begin{tabular}{|l|r|r|r|r|r|r|r|r|r|}
\hline Décennies & $\begin{array}{c}1791- \\
1799\end{array}$ & $\begin{array}{c}1800- \\
1810\end{array}$ & $\begin{array}{c}1811- \\
1820\end{array}$ & $\begin{array}{c}1821- \\
1830\end{array}$ & $\begin{array}{c}1831- \\
1840\end{array}$ & $\begin{array}{c}1841- \\
1850\end{array}$ & $\begin{array}{c}1851- \\
1860\end{array}$ & $\begin{array}{c}1861- \\
1870\end{array}$ & $\begin{array}{c}1871- \\
1880\end{array}$ \\
\hline Total peintres & 886 & 1939 & 1729 & 1825 & 8542 & 11492 & 5390 & 13652 & 10330 \\
\hline Peintres ant. & 161 & 241 & 191 & 139 & 79 & 188 & 137 & 575 & 254 \\
\hline $\begin{array}{l}\text { \% Peintres } \\
\begin{array}{l}\text { ant. / total } \\
\text { peintres }\end{array}\end{array}$ & $18,17 \%$ & $12,43 \%$ & $11,05 \%$ & $7,62 \%$ & $0,92 \%$ & $1,64 \%$ & $2,54 \%$ & $4,21 \%$ & $2,46 \%$ \\
\hline $\begin{array}{l}\text { Moy. / salon } \\
\text { peintres ant. }\end{array}$ & 27 & 34 & 48 & 46 & 9 & 19 & 27 & 64 & 39 \\
\hline
\end{tabular}

Tableau 3. Peintres « antiquisants »1791-1880

Un traitement des chiffres sur la base d'une périodisation liée à la succession des différents régimes politiques permet d'affiner cette observation (tableau 4).

Une première phase, couvrant la période révolutionnaire, le Consulat et l'Empire et une grande partie de la Restauration, est marquée par un déclin régulier en valeurs relatives. Toutefois, en valeurs absolues, le nombre de peintres “antiquisants » et de peintures à thèmes antiques reste important. Le pourcentage de peintures à thèmes antiques est autour de 12\% de 1791 à 1800 avec une pointe à 16,5\% en 1798, à un moment marqué par la domination de David, 


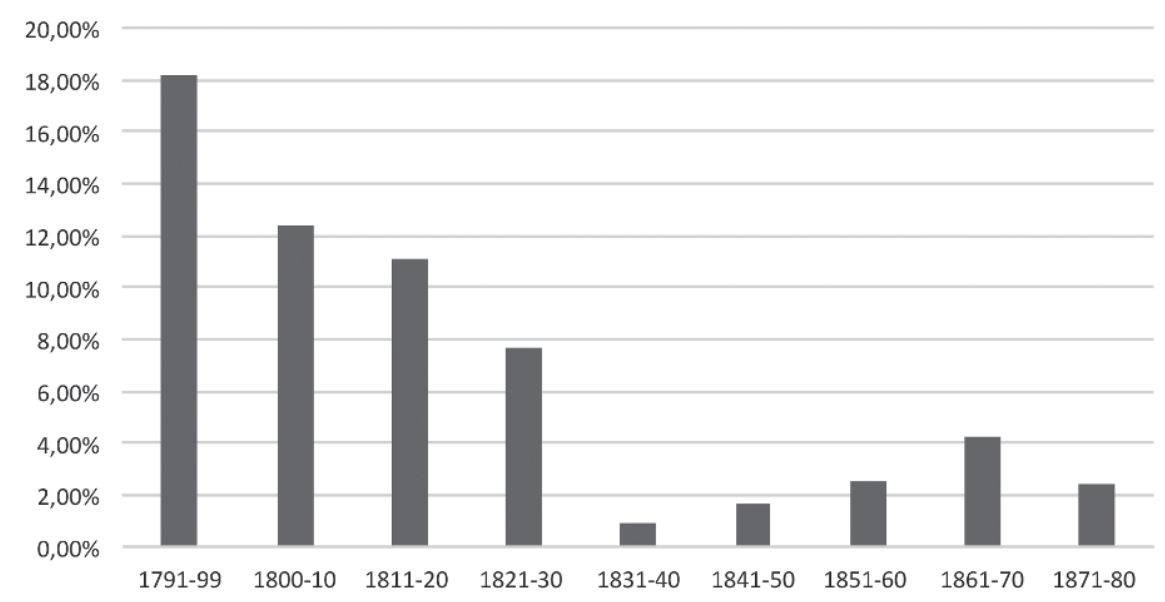

Graphique 2. Pourcentage peintres « antiquisants » / total peintres 1791-1880

\begin{tabular}{|c|c|c|c|c|c|c|c|}
\hline Régimes & $\begin{array}{c}\text { Période } \\
\text { révolu- } \\
\text { tionnaire } \\
(1791-1799) \\
\end{array}$ & $\begin{array}{c}\text { Consulat } \\
\text { et Empire } \\
(1800- \\
1814)\end{array}$ & $\begin{array}{c}\text { Restauration } \\
(1815-1829)\end{array}$ & $\begin{array}{c}\text { Monarchie } \\
\text { de Juillet } \\
(1830-1848)\end{array}$ & $\begin{array}{l}\text { Deuxième } \\
\text { République } \\
(1849-1851)\end{array}$ & $\begin{array}{c}\text { Second } \\
\text { Empire } \\
(1852- \\
1870)\end{array}$ & $\begin{array}{c}\text { Troisième } \\
\text { République } \\
(1872-1879)\end{array}$ \\
\hline $\begin{array}{l}\text { Notices } \\
\text { peintures } \\
\text { th. antiques } \\
\text { (total) }\end{array}$ & 307 & 415 & 306 & 207 & 107 & 783 & 296 \\
\hline $\begin{array}{l}\text { Notices } \\
\text { peintures th. } \\
\text { antiques (moy. } \\
\text { / salon) }\end{array}$ & 51 & 46 & 61 & 12 & 53 & 56 & 42 \\
\hline $\begin{array}{l}\% \text { peintures th. } \\
\text { antiques / total } \\
\text { peintures }\end{array}$ & $12,33 \%$ & $8,27 \%$ & $5,18 \%$ & $0,70 \%$ & $2,28 \%$ & $2,65 \%$ & $2,00 \%$ \\
\hline $\begin{array}{l}\text { Peintres ant. } \\
\text { (total) }\end{array}$ & 161 & 334 & 237 & 188 & 79 & 712 & 254 \\
\hline $\begin{array}{l}\text { Peintres ant. } \\
\text { (moy. / salon) }\end{array}$ & 27 & 37 & 47 & 11 & 39 & 51 & 36 \\
\hline $\begin{array}{l}\text { \% Peintres } \\
\text { ant. / total }\end{array}$ & $18,17 \%$ & $11,93 \%$ & $8,80 \%$ & $1,06 \%$ & $3,36 \%$ & $3,74 \%$ & $2,46 \%$ \\
\hline
\end{tabular}

Tableau 4. Peintures à thèmes antiques, peintres « antiquisants » et régimes politiques

maître incontesté de l'art néo-classique. Le nombre moyen par salon de peintres “ antiquisants » et de peintures à thèmes antiques continue même d'augmenter jusqu'au début des années 1820, alors que dans le même temps leur part tombe aux alentours de 6 à $7 \%$.

L'ouverture du Salon à tout un chacun n'a pas bouleversé d'un seul coup les habitudes des peintres : la tradition est bousculée, mais elle n'est pas moribonde. 
Bien que cette phase soit marquée par de profonds changements politiques, elle l'est aussi par une relative constance artistique. Le Premier Consul devenu Empereur (1804) aime l'art “ classique » (néo-classique) et David devient le peintre officiel du régime chargé de magnifier l'Empereur, tout en déplaçant le projecteur des thèmes « républicains » vers la célébration de l'Empire ${ }^{33}$. Les peintres, comme les sculpteurs d'ailleurs, restent imprégnés de la culture de l'Académie, faite d'apprentissage astreignant du dessin et d'étude de l'Antiquité, même si celleci est souvent abordée via les italiens de la Renaissance. Cela dit, les 16,5\% de peintures à thèmes antiques de 1798 sont dus au pinceau de $10 \%$ seulement des peintres exposant au Salon cette année-là, ce qui relativise l'importance - et l'attrait - de la culture antiquisante dans la population des artistes.

La deuxième phase correspond à un étiage de basses eaux de la peinture à thèmes antiques et de peintres “antiquisants ": il s'agit globalement de la Monarchie de Juillet, même si une chute accélérée est déjà observable au salon de 1827 et si l'année 1848 voit une remontée en flèche - mais la révolution a commencé fin février et le salon s'est tenu en mars, avec une très large ouverture aux exposants (plus de 5000 notices au total) ; l'atmosphère a déjà changé34. Louis Philippe privilégie la peinture d'histoire dans ses achats (ce qui ne peut manquer d'avoir un effet sur le marché de l'art), en particulier après sa décision de 1834 de créer un musée d'Histoire de France à Versailles. Au Salon de 1837, une seule notice est consacrée à la peinture à thèmes antiques, alors que le roi achète sur les crédits de la Maison du Roi quantité d'œuvres destinées à “ son » musée, dont des peintures de batailles en si grand nombre que les critiques se font peu aimables devant cette avalanche ${ }^{35}$.

La troisième phase est marquée par un nouvel intérêt pour l'Antiquité. Le nombre d'œuvres qui lui sont consacrées le montre et le pourcentage du nombre de peintures à thèmes antiques est en augmentation significative, et ce dès les débuts de la révolution de 1848. Pendant la brève vie de la Deuxième République, on voit le Salon renouer avec les sujets mythologiques ou littéraires tirés du fonds culturel gréco-latin. Le nombre moyen par salon de peintures à thèmes antiques

33 Voir E. Schwartz, D’Antigone à Marianne, pour les Prix de Rome.

34 F. de Lagenevais, “Le salon de 1848. La peinture ", Revue des Deux Mondes, 22, 1848, p. 282-299.

35 Voir A. BARbier, Le Salon de 1838, p.15-16 : « dorénavant, n’attendez rien de grand de vos artistes ; ce sera la moyenne propriété qui paiera et on lui en donnera pour son argent... vous aurez du petit, du joli, du soigné, et du bien conditionné, mais du grand jamais ! » Et Théophile Gautier, dans la Presse du 14 et du 23 février 1837, relève l'aspect théâtral et froid de la restauration du palais (Versailles) qu'il traite de " chambre funéraire », où le roi a logé “ dans cette ville morte toutes les gloires mortes, toutes les royautés mortes... tout est là depuis Clovis jusqu’à la révolution de juillet ». 
repasse au-dessus de 50 de 1849 à 1870, tandis que le nombre moyen de peintres " antiquisants » dépasse les 50 sous le Second Empire, atteignant un pic dans la seconde décennie du régime. La Maison de l'Empereur achète ces œuvres, comme Louis Philippe avait acheté les batailles de l'histoire de France. Les années 1860 sont celles d'une Antiquité qui n'a sans doute plus grand-chose à voir avec les héros de la Rome républicaine. Offenbach triomphe avec Orphée aux enfers (1858) et La Belle Hélène (1864), tandis que Napoléon III écrit une biographie de César et que le Prince Napoléon fait construire une villa pompéienne ${ }^{36}$. Nous y reviendrons en examinant les personnages représentés. Les valeurs absolues sont cependant quelque peu trompeuses : moins de $3 \%$ de peintures à thèmes antiques et un peu moins de $4 \%$ de peintres « antiquisants ».

La Troisième République sera marquée à ses débuts par une nouvelle, mais légère dégradation, dans un contexte perturbé : les peintres les plus novateurs secouent le joug des institutions ; des salons parallèles, concurrents ou carrément " antisystème », accueillent les peintres de plein air baptisés impressionnistes. Il reste que nombre de peintures du Salon « traditionnel » sont achetées par l'État et redistribuées dans les musées des villes de province ${ }^{37}$.

\section{Dieux, héros et mortels. Les personnages représentés}

L'Antiquité reste donc singulièrement présente, quoiqu'inégalement, tout au long de notre période. Encore faut-il savoir de quelle Antiquité il s'agit. À partir de la base de données du Musée d'Orsay et des livrets du Salon, nous avons constitué notre propre base de données sur les peintures à thèmes antiques du Salon. Elle compte plus de 5100 références de personnages ou de groupes. Nous les avons réparties en quatre ensembles : les dieux; le "petit peuple mythologique »; les héros et les personnages mythologiques et littéraires ; l'univers historique.

Nous retenons pour définir les dieux les trois caractéristiques données classiquement : immortalité, anthropomorphisme, pouvoir $(\mathbf{s})^{38}$. Dans la catégorie des dieux, nous distinguerons le dôdekathéôn ${ }^{39}$, les douze dieux dits majeurs, des autres dieux. Par " petit peuple mythologique », nous entendons les groupes de divinités mineures : nymphes, dryades, océanides, muses, satyres, faunes et

36 Voir: Spectaculaire Second Empire, Catalogue de l'Exposition au Musée d'Orsay (27 sept. 2016-17 janv. 2017), Paris 2016 ; Bacchanales modernes. Le nu, l'ivresse et la danse dans l'art français du xix siècle, sous la direction de S. Buratti-Hasan et S. Vitacca, Musée des Beaux-Arts de Bordeaux / Palais Fesch, Milan-Bordeaux 2016.

A. Chastel, “ Le paradis des peintres », p. 182.

38 A. Henrichs, "What is a Greek God? », in J.N. Bremmer, A. Erskine eds., The Gods of Ancient Greece, Edinburgh, 2010, p. 19.

39 I. Rutherford, “ Canonizing the Pantheon », ibidem, p. 43 s. 
silènes, etc. Elles sont souvent présentées de façon collective, mais, lorsqu'elles se trouvent insérées dans un récit et une scénographie spécifiques, certaines, nymphes et muses en particulier, peuvent être nommément désignées. Vient ensuite l'ensemble des héros et personnages mythologiques et littéraires, tels les héros homériques, ou encore Énée, Orphée, Psyché, Daphnis et Chloé, etc. Le dernier ensemble recouvre l'univers historique, grec et romain, parfois carthaginois (Hannibal) ou oriental (Antiochus), au sein duquel nous ferons une place à part aux auteurs littéraires et philosophes (Tableau 5, Graphique 3).

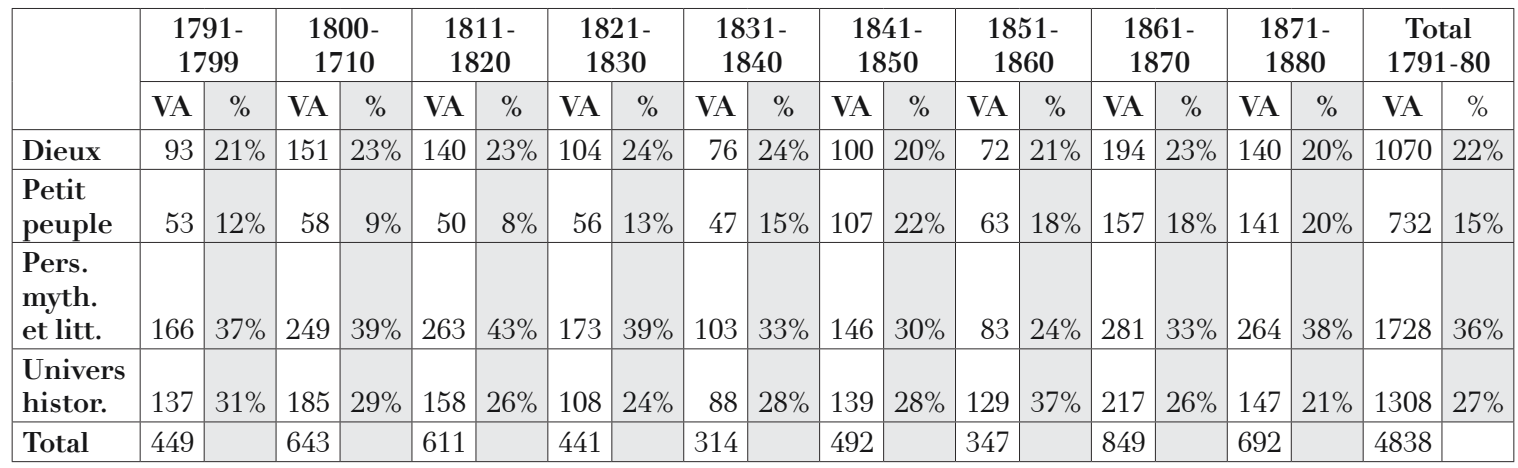

*VA : valeur absolue

Tableau 5. Dieux, petit peuple mythologique, héros et personnages mythologiques et littéraires, personnages historiques - Répartition par décennie 1791-1880

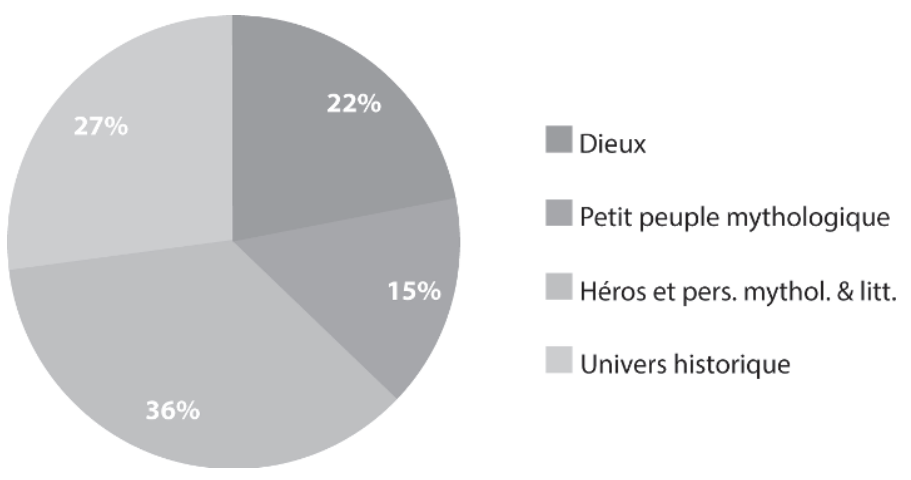

Graphique 3 : Dieux, petit peuple mythologique, héros et personnages mythologiques et littéraires, personnages historiques - Répartition en pourcentage 1791-1880

Avec les valeurs absolues, nous retrouvons le rythme ternaire déjà observé, sauf pour le “petit peuple mythologique » en augmentation à partir de 1841-50 (Graphique 4). 


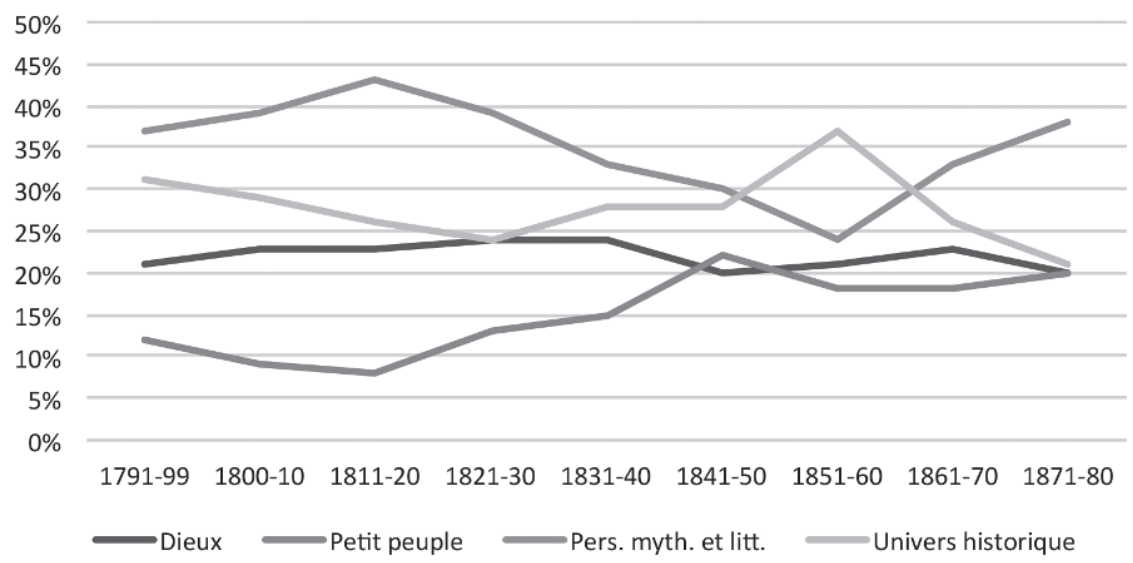

Graphique 4. Dieux, petit peuple mythologique, héros et personnages mythologiques et littéraires, univers historique - Répartition en pourcentage par décennie 1791-1880

La répartition en pourcentage par décennie montre la stabilité de la part des dieux. Elle confirme le rôle de plus en plus important du “petit peuple mythologique », cette fois-ci dès la fin de la Restauration. Elle manifeste une nette opposition entre les évolutions respectives des “ héros et personnages mythologiques et littéraires » et des personnages de l' « univers historique ».

Enfin, la somme des parts des dieux et du “petit peuple mythologique» marque la stabilité des représentations qui ont fait la “ grande peinture » depuis la Renaissance : les peintres ne renoncent pas à leurs acquis, le public semble continuer de les suivre, soutenus en cela par les institutions et par les figures des maîtres à penser de l'école. Ainsi donc, quand les héros et les personnages mythologiques et littéraires faiblissent à partir des années 1850, les personnages historiques prennent la relève comme autant de symboles, s'inscrivant en général dans une certaine actualité politico-historique.

Dans le même temps, les peintres “classiques" doivent faire front à la contestation des jeunes peintres que le Salon refuse. Ils doivent préserver leur marché tout en se dégageant des conventions académiques, leur approche évolue, s'appuyant sur de nouveaux codes. La Venus antique est encore présente, mais sous la figure de la petite marchande de statuette de Pompéi, scène gentille, plaisante, destinée à aller orner un salon de la bourgeoisie, bien que la bourgeoisie n'aie pas que des goûts que d'aucuns considéraient comme discutables... Les collectionneurs en effet vont bientôt commencer à acheter Monet ou ses compagnons, tandis que Gustave Moreau peint coup sur coup en 1864 et 1865, un Orphée (salon de 1866) et un Edipe et le Sphinx (salon de 1864) qui n’ont plus grand-chose de « classique ». 


\section{Les dieux}

\section{Le Dodékathéôn}

Ce sont les dieux dont le public qui fréquente le Salon peut se souvenir le plus facilement. Les cours de mythologie destinés aux classes secondaires relatent leurs histoires, les péripéties de leurs conquêtes, entre tueries fratricides et amours incestueux. Quel est leur succès de 1791 à 1880 ? Nous avons utilisé la liste canonique de ces douze divinités telle qu'elle s'est forgée dans le long processus de réception de la religion grecque ${ }^{40}$ (Tableau 6, Graphiques 5 et 6).

\begin{tabular}{|c|c|c|c|c|c|c|c|c|c|c|c|}
\hline Décennies & $\begin{array}{c}1791- \\
1799 \\
\end{array}$ & $\begin{array}{c}1800- \\
1810\end{array}$ & \begin{tabular}{|l}
$1811-$ \\
1820 \\
\end{tabular} & \begin{tabular}{|l|}
$1821-$ \\
1830 \\
\end{tabular} & \begin{tabular}{|l|}
$1831-$ \\
1840 \\
\end{tabular} & \begin{tabular}{|l|}
$1841-$ \\
1850 \\
\end{tabular} & $\begin{array}{l}1851- \\
1860\end{array}$ & \begin{tabular}{|l|}
$1861-$ \\
1870 \\
\end{tabular} & $\begin{array}{l}1871- \\
1880\end{array}$ & Total & $\%$ \\
\hline $\begin{array}{l}\text { Aphrodite/ } \\
\text { Vénus }\end{array}$ & 12 & 27 & 27 & 19 & 15 & 10 & 16 & 38 & 25 & 189 & $36,4 \%$ \\
\hline $\begin{array}{l}\text { Artémis/ } \\
\text { Diane }\end{array}$ & 8 & 9 & 10 & 6 & 3 & 12 & 5 & 21 & 17 & 91 & $17,5 \%$ \\
\hline $\begin{array}{l}\text { Zeus/ } \\
\text { Jupiter }\end{array}$ & 13 & 8 & 7 & 5 & 6 & 3 & 1 & 11 & 7 & 61 & $11,8 \%$ \\
\hline Apollon & 7 & 9 & 5 & 5 & 5 & 6 & 0 & 6 & 8 & 51 & $9,8 \%$ \\
\hline $\begin{array}{l}\text { Athéna/ } \\
\text { Minerve }\end{array}$ & 2 & 2 & 4 & 4 & 4 & 1 & 0 & 4 & 7 & 28 & $5,4 \%$ \\
\hline $\begin{array}{l}\text { Hermès/ } \\
\text { Mercure }\end{array}$ & 3 & 4 & 4 & 5 & 2 & 0 & 1 & 6 & 0 & 25 & $4,8 \%$ \\
\hline $\begin{array}{l}\text { Arès/ } \\
\text { Mars }\end{array}$ & 1 & 5 & 6 & 4 & 1 & 1 & 1 & 1 & 0 & 20 & $3,9 \%$ \\
\hline $\begin{array}{l}\text { Héra/ } \\
\text { Junon }\end{array}$ & 2 & 2 & 3 & 2 & 1 & 1 & 1 & 3 & 3 & 18 & $3,5 \%$ \\
\hline $\begin{array}{l}\text { Poséidon/ } \\
\text { Neptune }\end{array}$ & 0 & 4 & 2 & 3 & 1 & 0 & 0 & 1 & 2 & 13 & $2,5 \%$ \\
\hline $\begin{array}{l}\text { Héphaïstos/ } \\
\text { Vulcain }\end{array}$ & 0 & 3 & 1 & 1 & 3 & 1 & 0 & 0 & 2 & 11 & $2,1 \%$ \\
\hline $\begin{array}{l}\text { Déméter/ } \\
\text { Cérès }\end{array}$ & 0 & 2 & 3 & 1 & 0 & 1 & 0 & 3 & 0 & 10 & $1,9 \%$ \\
\hline $\begin{array}{l}\text { Hestia/ } \\
\text { Vesta }\end{array}$ & 1 & 0 & 0 & 0 & 0 & 0 & 0 & 0 & 1 & 2 & $0,4 \%$ \\
\hline Total & 49 & 75 & 72 & 55 & 41 & 36 & 25 & 94 & 72 & 519 & $100 \%$ \\
\hline $\begin{array}{l}\text { Moyenne } \\
\text { par salon }\end{array}$ & 8 & 11 & 18 & 18 & 5 & 4 & 5 & 10 & 10 & 9 & \\
\hline
\end{tabular}

Tableau 6. Représentations des 12 Olympiens par décennie

40 Voir E. Baldwin, Pantheon of the Ancient Historyof the Gods of Greece andRome, Londres, 1836; I. Rutherford, “ Canonizing the Pantheon ». Par ailleurs, le cours de Mythologie d'Alexandre Émile Lefranc, paru en 1829, mentionne en introduction à son travail le classement des dieux en cinq catégories : les grands dieux, les dieux subalternes, les dieux naturels, les dieux animés ou demi-dieux et les dieux allégoriques. La liste des “ grands dieux » correspond à celle que nous donnons des 12 Olympiens. 
Les déesses tiennent globalement le haut du pavé : si l'on ajoute à Aphrodite et Artémis, les quatre déesses les plus fréquemment représentées, Athéna, Héra, Déméter et Hestia, on est aux deux tiers des occurrences. Un rapide examen de l'évolution par décennie montre que le binôme Aphrodite-Artémis devient largement dominant à partir des années 1840 et que la représentation d'Aphrodite atteint des sommets dans la première décennie du Second Empire. Le binôme Zeus-Apollon ne fait (presque) jeu égal avec Aphrodite-Artémis que dans la décennie 1791-99.

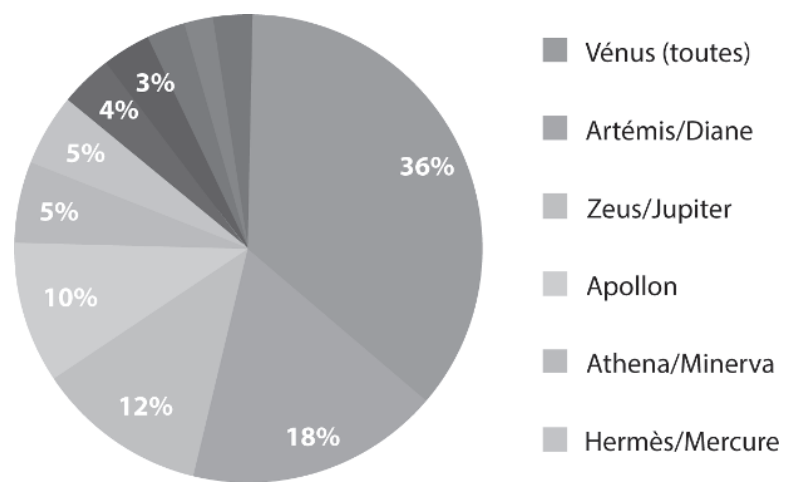

Graphique 5. Répartition en pourcentage des 12 Olympiens 1791-1880

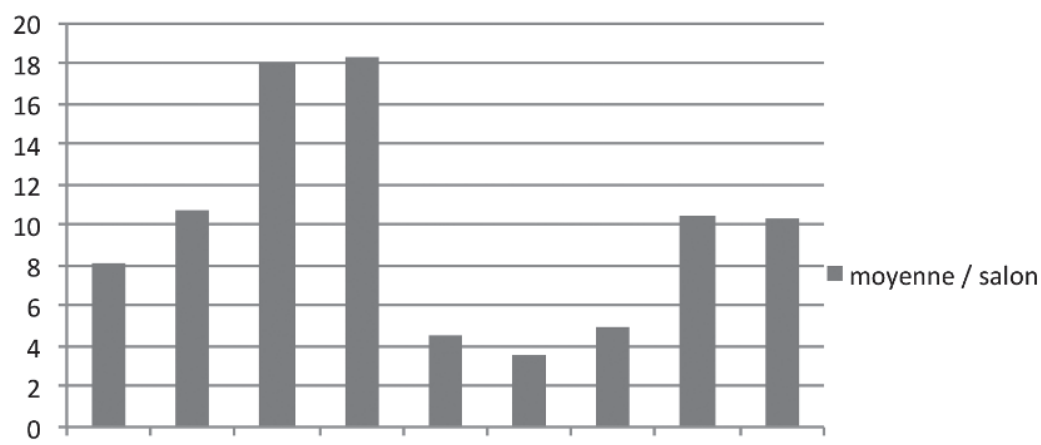

Graphique 6. Moyennes décennales par salon des 12 Olympiens 1791-1880

\section{Les autres dieux}

Les références aux autres dieux sont à peine plus nombreuses que celles aux douze Olympiens. Sur les 16 dieux qui ont été représentés, nous n'avons retenu que ceux dont les références étaient au minimum de 10. 
L'Amour, souvent nommé Cupidon, rarement Éros, écrase les autres références avec nettement plus de 50\% ${ }^{41}$. L'importance de l'Amour est liée pour une bonne part aux représentations inspirées des Métamorphoses d'Apulée avec le conte de Psyché (voir infra, p. 61-65). Il est suivi loin derrière par Bacchus (parfois sous le nom de Dionysos), lui-même suivi loin derrière par Hercule/ Héraclès $^{42}$ et Adonis $^{43}$. Les quatre mis ensemble frôlent les $80 \%$ de références (Tableau 7, Graphiques 7 et 8).

\begin{tabular}{|c|c|c|c|c|c|c|c|c|c|c|c|}
\hline Dieux & \begin{tabular}{|c|}
$1791-$ \\
1799 \\
\end{tabular} & $\begin{array}{l}1800- \\
1810\end{array}$ & $\begin{array}{c}1811- \\
1820 \\
\end{array}$ & \begin{tabular}{|l|}
$1821-$ \\
1830 \\
\end{tabular} & $\begin{array}{c}1831- \\
1840 \\
\end{array}$ & $\begin{array}{c}1841- \\
1850 \\
\end{array}$ & \begin{tabular}{|c|}
$1851-$ \\
1860 \\
\end{tabular} & \begin{tabular}{|c|}
$1861-$ \\
1870 \\
\end{tabular} & $\begin{array}{l}1871- \\
1880\end{array}$ & Total & $\%$ \\
\hline $\begin{array}{l}\text { Amour/Éros/ } \\
\text { Cupidon }\end{array}$ & 33 & 52 & 37 & 29 & 19 & 35 & 34 & 53 & 21 & 313 & $56,8 \%$ \\
\hline $\begin{array}{l}\text { Dionysos/ } \\
\text { Bacchus }\end{array}$ & 2 & 3 & 4 & 6 & 1 & 19 & 6 & 14 & 17 & 72 & $13,1 \%$ \\
\hline $\begin{array}{l}\text { Hercule/ } \\
\text { Héraclès }\end{array}$ & 4 & 3 & 8 & 2 & 5 & 3 & 0 & 10 & 8 & 43 & $7,8 \%$ \\
\hline Adonis & 0 & 6 & 7 & 2 & 3 & 1 & 2 & 5 & 5 & 31 & $5,6 \%$ \\
\hline Pan & 0 & 2 & 3 & 2 & 1 & 2 & 0 & 6 & 3 & 19 & $3,4 \%$ \\
\hline Eos/Aurore & 1 & 2 & 1 & 0 & 1 & 2 & 2 & 2 & 2 & 13 & $2,4 \%$ \\
\hline Circé & & 1 & 1 & 1 & 2 & 0 & 0 & 1 & 5 & 11 & $2,0 \%$ \\
\hline Hébé & 2 & 2 & 0 & 1 & 1 & 1 & 1 & 2 & 0 & 10 & $1,8 \%$ \\
\hline $\begin{array}{l}\text { Perséphone/ } \\
\text { Proserpine }\end{array}$ & 0 & 3 & 2 & 3 & 0 & 0 & 1 & 1 & 0 & 10 & $1,8 \%$ \\
\hline Autres & 2 & 2 & 5 & 3 & 2 & 1 & 1 & 6 & 7 & 29 & $5,3 \%$ \\
\hline Total & 44 & 76 & 68 & 49 & 35 & 64 & 47 & 100 & 68 & 551 & \\
\hline $\begin{array}{l}\text { Moyennel } \\
\text { salon }\end{array}$ & 7 & 11 & 17 & 16 & 4 & 6 & 9 & 11 & 10 & 9 & $100,0 \%$ \\
\hline
\end{tabular}

Tableau 7. Représentations des autres dieux par décennie 1791-1880

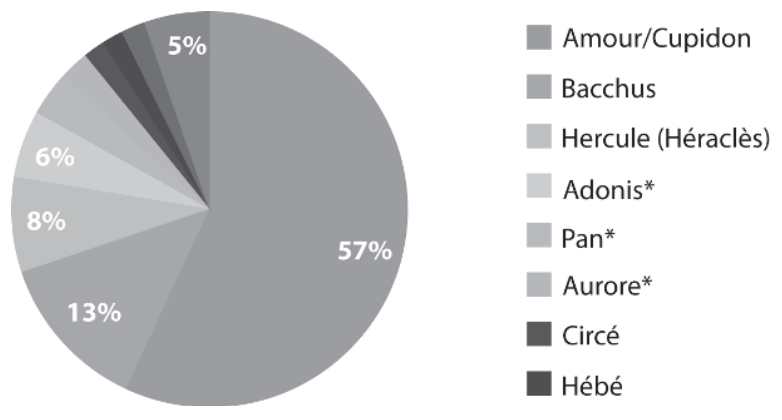

Graphique 7.

Répartition en pourcentage des autres dieux 1791-1880

41 Rappelons que nous n'avons pas retenu les références aux « amours », mais seulement celles à l’ “ Amour » comme divinité (voir ci-dessus, p. 3).

42 Héraclès est d'abord un héros, mais devient ensuite immortel, ce qui se traduit par son accession au rang de dieu.

43 Adonis constitue un cas limite : amant d'Aphrodite (et de Perséphone), il est mortel, mais un culte lui est rendu, et c'est en même temps une divinité d'origine orientale. 


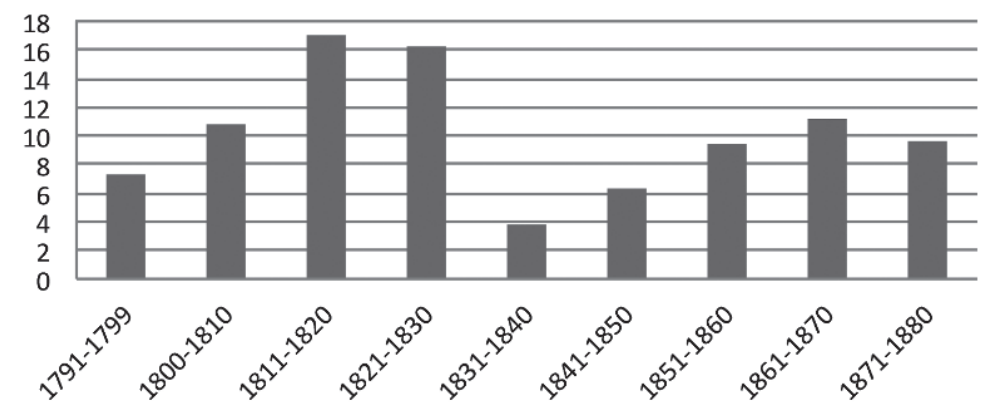

Graphique 8. Moyennes décennales par salon des autres dieux 1791-1880

Au total, Aphrodite/Vénus et l'Amour dominent nettement les représentations des dieux et déesses. Ils connaissent deux âges d'or, à la fin de l'Empire et surtout sous la Restauration d'une part, sous le Second Empire d'autre part.

\section{Le petit peuple mythologique}

Ce petit peuple est largement dominé par les Nymphes (certaines nommément désignées) et par les Bacchantes (ou Ménades). Ces personnages féminins sont suivis par les éléments masculins du cortège dionysiaque - Satyres, Faunes, Silènes. Grâces et Muses viennent loin derrière. La catégorie « autres » comprend Océanides, Centaures, Parques, Furies, Dieux lares et pénates... avec un cinquième des références (Tableau 8, Graphiques 9 et 10).

\begin{tabular}{|c|c|c|c|c|c|c|c|c|c|c|c|}
\hline & \begin{tabular}{|l|}
$1791-$ \\
1799 \\
\end{tabular} & $\begin{array}{c}1800- \\
1810\end{array}$ & $\begin{array}{l}1811- \\
1820\end{array}$ & $\begin{array}{c}1821- \\
1830\end{array}$ & $\begin{array}{c}1831- \\
1840\end{array}$ & $\begin{array}{l}1841- \\
1850\end{array}$ & $\begin{array}{c}1851- \\
1860\end{array}$ & $\begin{array}{c}1861- \\
1870 \\
\end{array}$ & $\begin{array}{l}1871- \\
1880\end{array}$ & Total & $\%$ \\
\hline $\begin{array}{l}\text { Nymphes, } \\
\text { naïades, } \\
\text { dryades }\end{array}$ & 22 & 33 & 27 & 32 & 20 & 48 & 28 & 84 & 77 & 371 & $50,68 \%$ \\
\hline $\begin{array}{l}\text { Bacchantes/ } \\
\text { Ménades }\end{array}$ & 19 & 8 & 2 & 3 & 8 & 23 & 11 & 15 & 10 & 99 & $13,52 \%$ \\
\hline $\begin{array}{l}\text { Satyres, } \\
\text { Faunes, } \\
\text { Silènes }\end{array}$ & 2 & 1 & 4 & 3 & 7 & 11 & 6 & 16 & 22 & 72 & $9,84 \%$ \\
\hline Grâces & 2 & 2 & 1 & 1 & 3 & 2 & 2 & 5 & 0 & 18 & $2,46 \%$ \\
\hline Muses & 0 & 1 & 3 & 2 & 1 & 1 & 1 & 3 & 4 & 16 & $2,19 \%$ \\
\hline Autres & 8 & 13 & 13 & 15 & 8 & 22 & 15 & 34 & 28 & 156 & $21,31 \%$ \\
\hline Total & 53 & 58 & 50 & 56 & 47 & 107 & 63 & 157 & 141 & 732 & $100,00 \%$ \\
\hline $\begin{array}{l}\text { Moyenne/ } \\
\text { salon }\end{array}$ & 9 & 8 & 12,5 & 19 & 5 & 11 & 13 & 17 & 20 & 12 & \\
\hline
\end{tabular}

Tableau 8. Représentations du petit peuple mythologique par décennie 1791-1880 


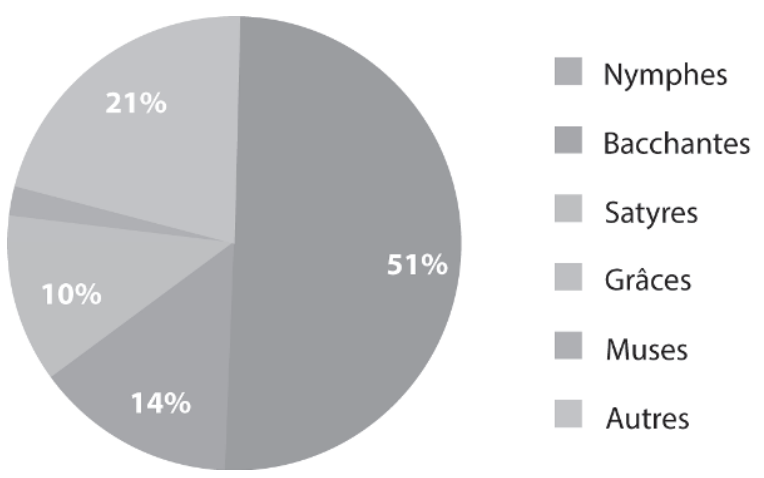

Graphique 9. Répartition en pourcentage des catégories du petit peuple mythologique 1791-1880

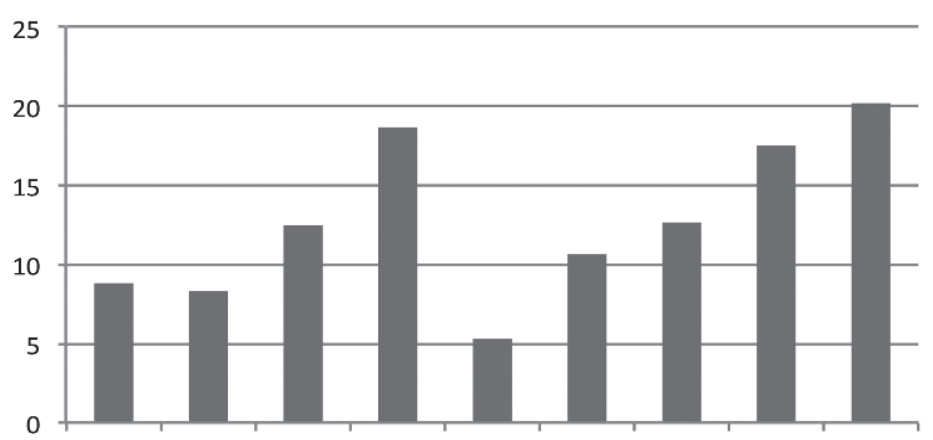

Graphique 10. Moyennes décennales par salon du petit peuple mythologique 1791-1880

L'âge d'or du petit peuple mythologique se situe tout autant à la fin du Second Empire et dans les débuts de la Troisième République, que sous la Restauration. L'élément féminin domine, avec une échelle dans la sensualité qui va croissant des Nymphes aux Bacchantes ${ }^{44}$; les débuts de la Troisième République sont marqués néanmoins par le succès des Satyres, Faunes et Silènes. Avec les Nymphes, le répertoire ovidien pointe le nez (voir § III).

\section{Héros et personnages mythologiques et littéraires}

Nous avons réparti cet ensemble, le plus fourni de tous (36\%), en cinq catégories: les personnages homériques en y incluant ceux du Télémaque de Fénelon; les personnages virgiliens; les personnages des tragiques grecs; les personnages des deux “ romans » du $\mathrm{II}^{\mathrm{e}} / \mathrm{III}^{\mathrm{e}}$ siècle après J.-C., les Métamorphoses

44 Voir Bacchanales modernes, op.cit., p. 173. 
d'Apulée et Daphnis et Chloé de Longus; le “ répertoire ovidien ». Nous avons tenté de répondre au mieux aux quelques problèmes de répartition entre catégories ${ }^{45}$. S'ajoute à ces catégories une sixième, “ autres », assez substantielle. Elle se signale par la présence de héros et personnages issus de quelques grands mythes : Thésée, Prométhée, Orphée ${ }^{46}$, les deux premiers ayant un poids un peu supérieur aux personnages virgiliens. Si nous avons décidé de maintenir une ligne spécifique pour les personnages virgiliens dans le tableau 9, c'est pour souligner, dans la sphère de l'épopée, l'énorme décalage des représentations entre le monde d'Homère et celui de Virgile, ainsi que le déclin relatif des deux groupes au fil des décennies (Tableau 9, Graphiques 11 et 12).

\begin{tabular}{|c|c|c|c|c|c|c|c|c|c|c|c|}
\hline Catégories & $\begin{array}{c}1791- \\
1799\end{array}$ & $\begin{array}{c}1800- \\
1810\end{array}$ & $\begin{array}{c}1811- \\
1820\end{array}$ & $\begin{array}{c}1821- \\
1830\end{array}$ & $\begin{array}{c}1831- \\
1840\end{array}$ & $\begin{array}{c}1841- \\
1850\end{array}$ & $\begin{array}{l}1851- \\
1860\end{array}$ & $\begin{array}{l}1861- \\
1870\end{array}$ & $\begin{array}{c}1871- \\
1880\end{array}$ & $\begin{array}{c}\text { Total } \\
1791- \\
1880\end{array}$ & $\begin{array}{c}\% \\
1791- \\
1880\end{array}$ \\
\hline $\begin{array}{l}\text { Homère } \\
\text { (et Télémaque) }\end{array}$ & 48 & 84 & 85 & 47 & 35 & 17 & 5 & 40 & 30 & 391 & $22,63 \%$ \\
\hline Moyenne/salon & 8 & 12 & 21,25 & 15,67 & 3,89 & 1,7 & 1 & 4,44 & 4,29 & 6,52 & \\
\hline Virgile & 10 & 7 & 19 & 8 & 2 & 3 & 5 & 5 & 7 & 66 & $3,82 \%$ \\
\hline Moyenne/salon & 1,67 & 1 & 4,75 & 2,67 & 0,22 & 0,3 & 1 & 0,55 & 1 & 1,1 & \\
\hline Tragiques & 24 & 45 & 50 & 17 & 10 & 10 & 9 & 27 & 23 & 215 & $12,44 \%$ \\
\hline Moyenne/salon & 4 & 6,43 & 12,5 & 5,67 & 1,11 & 1 & 1,8 & 3 & 3,29 & 3,58 & \\
\hline $\begin{array}{l}\text { Apulée } \\
\text { et Longus }\end{array}$ & 11 & 26 & 18 & 33 & 17 & 33 & 14 & 51 & 46 & 249 & $14,41 \%$ \\
\hline Moyenne/. & 1,83 & 3,71 & 4,5 & 11 & 1,89 & 3,3 & 2,8 & 5,67 & 6,57 & 4,15 & \\
\hline Ovide & 45 & 47 & 50 & 46 & 28 & 46 & 20 & 92 & 83 & 457 & $26,45 \%$ \\
\hline Moyenne/salon & 7,5 & 6,71 & 12,5 & 15,33 & 3,11 & 4,6 & 4 & 10,22 & 11,86 & 7,62 & \\
\hline Autres & 28 & 40 & 41 & 22 & 11 & 37 & 30 & 66 & 75 & 350 & $20,25 \%$ \\
\hline Total & 166 & 249 & 263 & 173 & 103 & 146 & 83 & 281 & 264 & 1728 & $100,00 \%$ \\
\hline Moyenne/salon & 27,67 & 35,57 & 65,75 & 57,67 & 11,44 & 14,6 & 16,6 & 31,22 & 37,71 & 28,8 & \\
\hline
\end{tabular}

Tableau 9. Répartition par décennie des catégories de héros et personnages mythologiques et littéraires

45 Ainsi, nous avons conservé chez Homère Agamemnon, bien qu'il puisse être compté dans les personnages des tragiques; à l'inverse, nous avons compté Iphigénie et Cassandre au nombre des personnages des tragiques, alors qu'elles relèvent aussi du monde homérique. Ces choix ne sont pas arbitraires, ils résultent tant du contexte dans lequel ces personnages sont généralement représentés que de ce que nous savons des connaissances littéraires de certains peintres, Ingres en particulier.

46 Orphée et Eurydice auraient pu être comptés avec les héros virgiliens, du fait du récit inclus dans les Géorgiques, IV, ou dans le répertoire ovidien (Métamorphoses, X-XI). Nous avons jugé préférable de ne pas leur rattacher le mythe d'Orphée du fait de sa grande popularité. 


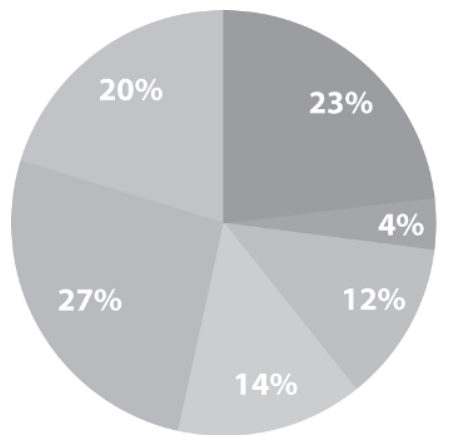

Personnages homériques (et du Télémaque)

Graphique 11. Répartition en pourcentage des catégories de héros et personnages mythologiques et littéraires 1791-1880

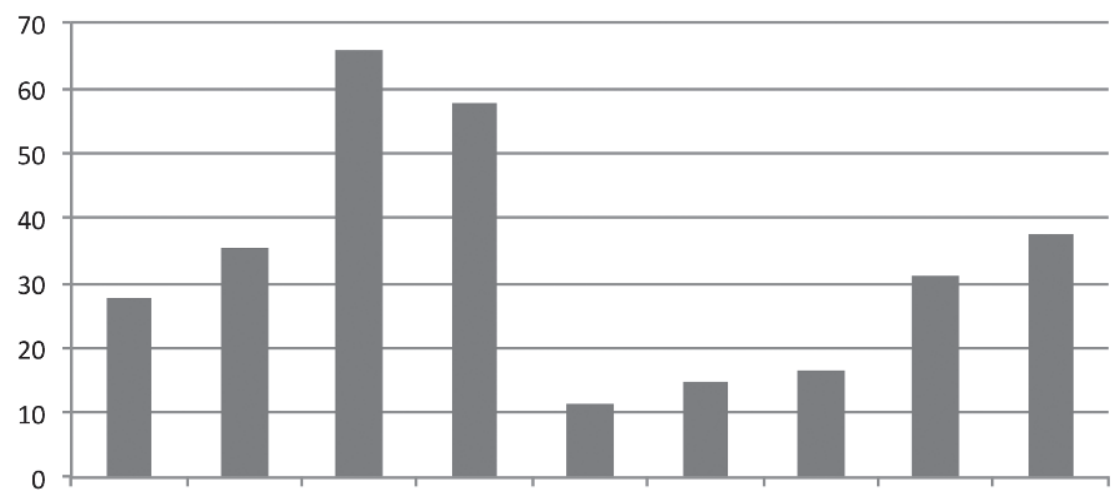

Graphique 12. Moyennes décennales par salon des héros et personnages mythologiques et littéraires 1791-1880

En chiffres totaux, comme en moyennes par salon, les maxima des personnages homériques ${ }^{47}$, virgiliens, et de ceux des tragiques grecs, se situent dans la décennie 1811-20 (avec des extensions sur la décennie 1821-30 pour les homériques). Le répertoire ovidien, ainsi que les personnages d'Apulée et de Longus connaissent leur sommet en chiffres totaux entre 1860 et 1880, tandis que les moyennes par Salon révèlent un double “ pic », sous la Restauration et en fin de période ; il en va de même pour les mythes de Prométhée, Orphée et Thésée (Graphique 13).

47 Notons que les personnages de l'Iliade l'emportent nettement (70\%) sur ceux de l'Odyssée. La seule décennie où les deux groupes font pratiquement jeu égal est 1861-1870. 


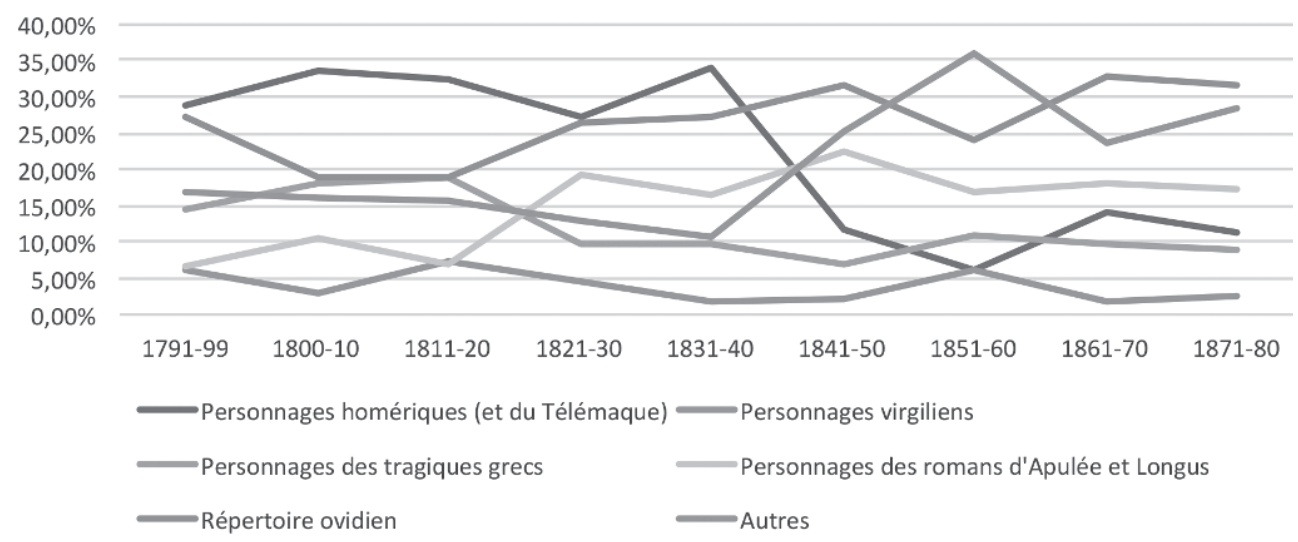

Graphique 13. Répartition en pourcentage par décennie des catégories de héros et personnages mythologiques et littéraires 1791-1880

L'analyse décennale fait apparaître des changements substantiels. Pendant la période révolutionnaire (1791-99), les personnages homériques et ceux du répertoire ovidien tiennent le premier rang à parts presque égales, tandis qu'en fin de période (1861-80), le répertoire ovidien se retrouve seul en tête. Les personnages homériques et virgiliens, ceux des tragiques grecs cèdent devant ceux du répertoire ovidien et des fictions d'Apulée et Longus. En parallèle, on note un élargissement de l'éventail des personnages représentés ${ }^{48}$.

\section{Univers historique}

La part de ce dernier ensemble évolue au fil des décennies quasiment à l'inverse du précédent. Après avoir représenté environ 30\% des occurrences entre 1791 et 1810, il a connu son apogée dans la première décennie du Second Empire (37\%) avant de retomber au niveau d'un cinquième dans les débuts de la Troisième République.

Nous avons réparti ces personnages en quatre catégories : les personnages relevant de l'histoire grecque; ceux relevant de l'histoire romaine; les

48 Exemples de personnages témoignant de cette diversification: Damoclès, Midas, Jason, etc., auxquels viennent s'ajouter des personnages " néo-antiques » issus de la littérature du xvıI ${ }^{\mathrm{e}}$ siècle comme Pannychis (Chénier, Bucoliques) ou Amyntas (Gessner, Idylles). 


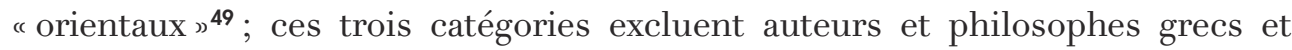
romains que nous avons rangés dans une dernière catégorie. Ici encore, les frontières entre les quatre catégories ne sont pas toujours faciles à établir ${ }^{50}$ (Tableau 10, Graphiques 14 et 15).

\begin{tabular}{|c|c|c|c|c|c|c|c|c|c|c|}
\hline Catégories & $\begin{array}{c}1791- \\
1799\end{array}$ & $\begin{array}{c}1800- \\
1810\end{array}$ & $\begin{array}{c}1811- \\
1820\end{array}$ & $\begin{array}{l}1821- \\
1830\end{array}$ & $\begin{array}{c}1831- \\
1840\end{array}$ & $\begin{array}{c}1841- \\
1850\end{array}$ & $\begin{array}{c}1851- \\
1860\end{array}$ & $\begin{array}{c}1861- \\
1870\end{array}$ & $\begin{array}{c}1871- \\
1880\end{array}$ & $\begin{array}{c}\text { Total } \\
\text { 1791-1880 }\end{array}$ \\
\hline Grecs & 45 & 73 & 59 & 22 & 21 & 27 & 21 & 34 & 25 & 327 \\
\hline $\begin{array}{l}\text { Moyenne/ } \\
\text { salon }\end{array}$ & 7,50 & 10,43 & 14,75 & 7,33 & 2,33 & 2,70 & 4,20 & 3,78 & 3,57 & 5,45 \\
\hline Romains & 70 & 66 & 60 & 58 & 48 & 70 & 84 & 140 & 91 & 687 \\
\hline $\begin{array}{l}\text { Moyenne/ } \\
\text { salon }\end{array}$ & 11,67 & 9,43 & 15,00 & 19,33 & 5,33 & 7,00 & 16,80 & 15,56 & 13,00 & 11,45 \\
\hline Orientaux & 3 & 9 & 6 & 2 & 0 & 4 & 4 & 3 & 1 & 32 \\
\hline $\begin{array}{l}\text { Moyenne/ } \\
\text { salon }\end{array}$ & 0,50 & 1,29 & 1,50 & 0,67 & 0,00 & 0,40 & 0,80 & 0,33 & 0,14 & 0,53 \\
\hline $\begin{array}{l}\text { Auteurs et } \\
\text { philosophes }\end{array}$ & 19 & 37 & 33 & 26 & 19 & 38 & 20 & 40 & 30 & 262 \\
\hline $\begin{array}{l}\text { Moyenne/ } \\
\text { salon }\end{array}$ & 3,17 & 5,29 & 8,25 & 8,67 & 2,11 & 3,80 & 4,00 & 4,44 & 4,29 & 4,37 \\
\hline Total & 137 & 184 & 158 & 108 & 88 & 139 & 129 & 217 & 147 & 1308 \\
\hline $\begin{array}{l}\text { Moyenne / } \\
\text { salon }\end{array}$ & 22,83 & 26,29 & 39,50 & 36,00 & 9,78 & 13,90 & 25,80 & 24,11 & 21,00 & 21,80 \\
\hline
\end{tabular}

Tableau 10. Catégories de l'univers historique - Répartition par décennie 1791-1880

La prépondérance des Romains est globalement très marquée avec plus de la moitié des occurrences, soit légèrement plus du double de la part des Grecs.

49 Pour l'essentiel, des personnages de l'empire perse.

50 Ainsi avons-nous mis Cicéron, Démosthène et Marc-Aurèle chez les « auteurs et philosophes » du fait du contexte retenu par les peintres qui les ont représentés ; nous en avons en revanche exclu César, son rôle historique apparaissant primordial par rapport à sa qualité d'écrivain. Nous avons compté la dynastie des Ptolémées parmi les “ Grecs » en tant qu'héritiers d'Alexandre. Notre vision des « Romains » est extensive : elle inclut les peuples et individus que les Romains ont combattus, les personnages qui ont joué un rôle dans l'histoire de Rome bien que non Romains, et Romulus et Rémus car, bien que légendaires, ils font partie de cette histoire, telle qu'elle a été écrite par les historiens antiques. 


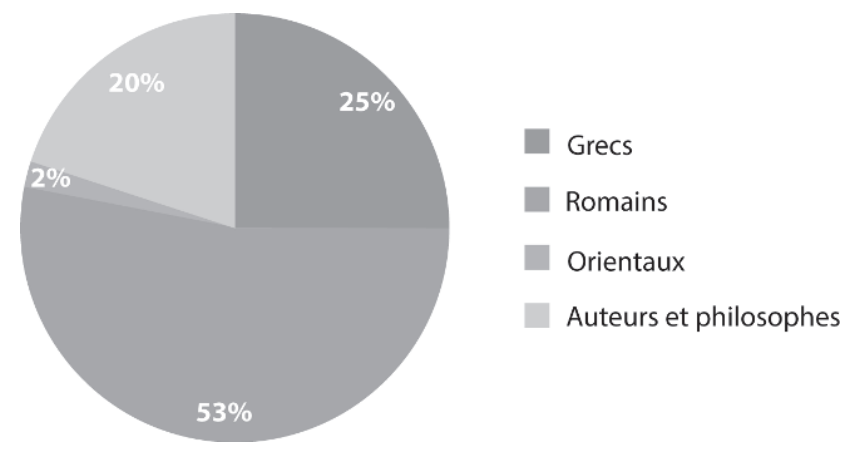

Graphique 14. Répartition en pourcentage des catégories de personnages de l'univers historique 1791-1880

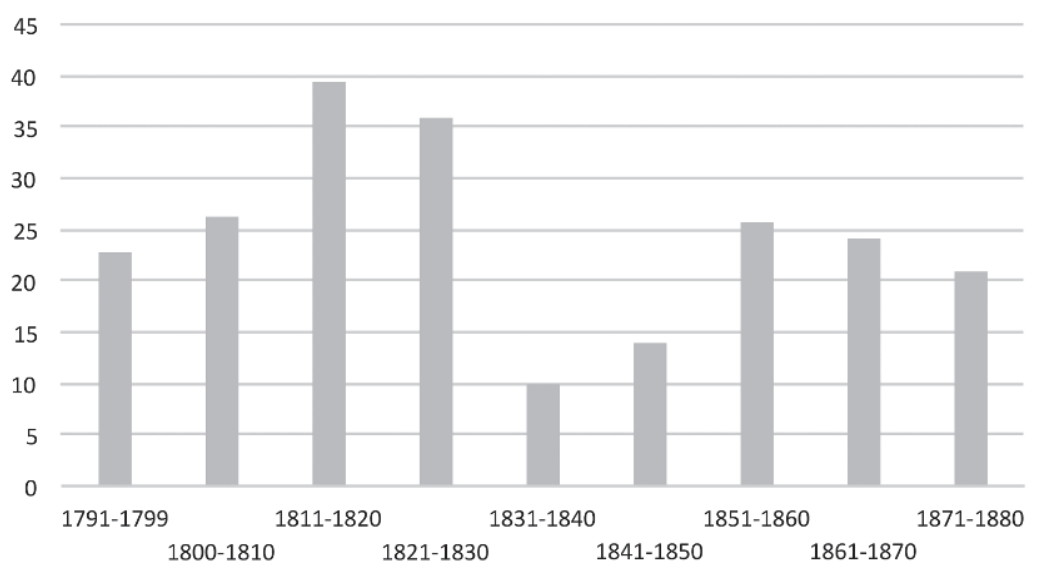

Graphique 15. Moyennes décennales par salon des personnages de l'univers historique 1791-1880

Au fil des décennies, si les parts des “ Orientaux » et des auteurs et philosophes ne varient guère, on observe une évolution complètement opposée des parts respectives des Grecs et des Romains : les Romains triomphent pendant la période révolutionnaire, puis Grecs et Romains font quasiment jeu égal pendant une vingtaine d'années (1800-20) ; les Romains font un grand retour sous le Second Empire et dans les débuts de la Troisième République (Graphique 16).

Chez les Grecs, les individus les plus fréquemment représentés sont par ordre décroissant Alexandre, Alcibiade, Phrynés1, Archimède, Antiochus et Périclès.

51 Les courtisanes, nommées ou non, sont particulièrement représentées sous le Second Empire, Phryné en premier lieu. 
Les personnages de l'époque préclassique et classique l'emportent presque dans un rapport de deux à un sur ceux de l'époque hellénistique.

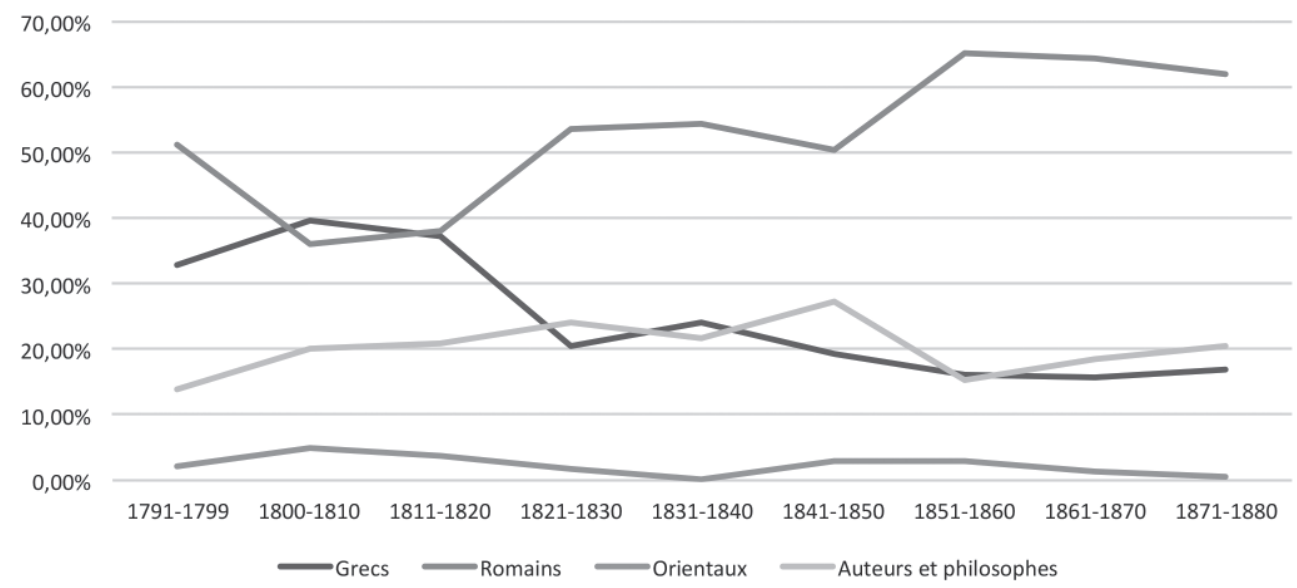

Graphique 16. Répartition par décennie en pourcentage des catégories de personnages de l'univers historique 1791-1880

Chez les Romains, nous rencontrons deux “pics» équivalents: sous la Restauration et sous le Second Empire. César arrive très largement en tête, suivi de Cléopâtre, Néron et Auguste ; viennent ensuite Lucrèce, Marius, Junius Brutus $^{52}$, Bélisaire ${ }^{53}$ et Antoine. La Rome archaïque regroupe une centaine de représentations, tandis que la République d'une part, et l'Empire à partir d'Auguste d'autre part, en regroupent chacun un peu plus de 200. Les héros de la période républicaine (Cincinnatus, Mucius Scaevola, Regulus...) ont sans surprise la faveur de la décennie 1791-9954. Pendant la période 1811-30, qui est celle de l' “ascension » des Romains, les personnages de la période archaïque reculent nettement, et sous le Second Empire, ce recul prend des allures de débâcle au bénéfice des personnages de la fin de la République (César, Cléopâtre, Antoine, Brutus...) et de ceux de l'Empire. César, objet de l'intérêt de Napoléon III, est représenté avec la plus grande fréquence sous le Second Empire.

52 L’autre Brutus, assassin de César, ne bénéficie que de 11 occurrences.

53 Cas un peu particulier: Bélisaire, le général de l'empereur Justinien - donc un personnage très tardif ( $\mathrm{vI}^{\mathrm{e}}$ siècle) : le Bélisaire demandant l'aumône de David (1780) ainsi que le conte philosophique de Jean-François Marmontel de 1767 sont sans doute largement responsables de cette relative “ popularité ».

54 Les personnages de la période républicaine sont aussi nombreux que la somme de ceux de la période archaïque et de l'Empire. 
Chez les auteurs et philosophes, Sappho mène amplement, suivie loin derrière par Homère ${ }^{55}$. Vient ensuite un groupe de cinq personnages : par ordre décroissant, Virgile, Diogène, Socrate, Anacréon et Horace. Les Grecs l'emportent largement sur les Romains, à l'inverse des autres groupes. Si la place d'Homère n'est pas surprenante - la représentation de l'aède aveugle est pratiquement un topos, celle de Sappho nous semble l'être davantage, en particulier si l'on note qu'elle est présente tout au long de notre période, mise en scène à Leucade ou bien encore avec Phaon ${ }^{56}$. La liste d'auteurs établie à partir des Salons correspond assez bien au “panthéon littéraire » d'Ingres ${ }^{57}$, comme l'illustre son Apothéose d'Homère (1827).

\section{À la poursuite des sources littéraires antiques}

Seule une assez petite minorité de peintres (12\%) juge nécessaire d'indiquer la source littéraire, assez souvent accompagnée d'une citation, sur laquelle ils s'appuient et dont ils s'inspirent. La période la plus riche en références explicites couvre la Monarchie de Juillet, la Deuxième République et la première décennie du Second Empire (19\%): les peintres exposant au Salon semblent alors manifester un intérêt accru pour rattacher explicitement leur sujet à une source littéraire antique.

Le tableau suivant ne comporte que les références représentant plus de $5 \%$ du total. Nous avons regroupé les références à Suétone et Tacite d'une part, et celles aux tragiques grecs d'autre part (Tableau 11).

\begin{tabular}{|c|c|c|c|c|c|c|c|c|c|c|c|}
\hline Auteurs & $\begin{array}{l}1791- \\
1799\end{array}$ & $\begin{array}{l}1800- \\
1810\end{array}$ & \begin{tabular}{|l|}
$1811-$ \\
1820
\end{tabular} & $\begin{array}{l}1821- \\
1830\end{array}$ & $\begin{array}{l}1831- \\
1840\end{array}$ & $\begin{array}{l}1841- \\
1850\end{array}$ & $\begin{array}{l}1851- \\
1860\end{array}$ & $\begin{array}{l}1861- \\
1870\end{array}$ & $\begin{array}{l}1871- \\
1880\end{array}$ & Total & $\%$ \\
\hline Homère & 3 & 1 & 1 & 2 & 1 & 2 & 2 & 4 & 4 & 20 & $7 \%$ \\
\hline Ovide & 0 & 7 & 2 & 2 & 2 & 8 & 3 & 20 & 10 & 54 & $19 \%$ \\
\hline Plutarque & 0 & 4 & 1 & 1 & 3 & 6 & 1 & 6 & 2 & 24 & $8 \%$ \\
\hline Tragiques & 0 & 1 & 3 & 3 & 0 & 5 & 2 & 6 & 4 & 24 & $8 \%$ \\
\hline $\begin{array}{l}\text { Suétone + } \\
\text { Tacite }\end{array}$ & 0 & 1 & 1 & 1 & 2 & 5 & 4 & 9 & 3 & 26 & $9 \%$ \\
\hline Virgile & 1 & 4 & 3 & 3 & 2 & 9 & 5 & 11 & 6 & 44 & $15 \%$ \\
\hline $\begin{array}{l}\text { Total tous } \\
\text { auteurs }\end{array}$ & 5 & 27 & 19 & 18 & 15 & 44 & 33 & 81 & 45 & 287 & $100 \%$ \\
\hline
\end{tabular}

Tableau 11. Références explicites à des auteurs par décennie 1791-1880

Sachant que 37 auteurs au total ont été répertoriés, nous avons constaté un maximum de dispersion sur des auteurs différents pendant la période 1811-30, ce

55 Considéré ici par convention comme un personnage historique.

56 Voir Ovide, Hérö̈des, XV.

57 N. SCHLÉNOFF, Ingres, p. $148 \mathrm{~s}$. 
qui manifeste peut-être une plus forte prégnance - authenticité ? - de la culture littéraire antique.

Les deux poètes latins du règne d'Auguste sortent grands vainqueurs, suivis par un trio d'historiens, Plutarque avec ses Vies, et le couple Tacite-Suétone. La place d'Homère est significative, encore qu'elle soit relativement modeste. Absences ou quasi-absences notables chez les historiens : Thucydide et Xénophon. L'analyse par décennie révèle deux éléments : Ovide bénéficie d'un intérêt soutenu en fin de période, en particulier dans la seconde décennie du Second Empire ; les historiens classiques (Plutarque, Suétone, Tacite, Tite-Live) et César (“popularisé » sous le Second Empire par Napoléon III lui-même ${ }^{58}$ ) durant la seconde moitié de la Monarchie de Juillet et le Second Empire.

On peut tenter d'aller un petit peu plus loin dans l'analyse des sources littéraires, quoiqu'en terrain incontestablement moins ferme, en évoquant les sources " probables». En effet, un nombre significatif de tableaux, de par le sujet représenté, renvoie avec un degré de probabilité élevé à des sources $a$ priori clairement identifiables. Il en va ainsi notamment pour les personnages de l'Iliade et de l'Odyssée, pour Daphnis et Chloé qui renvoient au roman éponyme de Longus, pour Psyché et les thèmes issus des Métamorphoses d'Apulée, pour certains sujets tirés de l'Énéide (voire des Bucoliques) de Virgile, encore qu'Enée soit aussi un personnage homérique. Pour Télémaque, personnage homérique, mais aussi personnage des Aventures de Télémaque de Fénelon (1699), nous avons retenu en principe la source homérique, sauf lorsque le sujet et son contexte renvoyaient clairement à Fénelon ${ }^{59}$.

Les Métamorphoses d'Ovide posent un problème un peu plus complexe ${ }^{60}$. La source antique ${ }^{61}$ ovidienne se trouve en concurrence avec un trio bien connu, la Bibliothèque d'Apollodore, les Fables d'Hygin, le Voyage ou Description de la Grèce de Pausanias (et éventuellement la Bibliothèque historique de Diodore de Sicile). Nous avons donné la priorité à Ovide, considérant qu'il offrait - et ce depuis la Renaissance - la source la plus connue, et le répertoire le plus riche. La situation est assez voisine avec les Vies de Plutarque, largement connues et dans diverses

58 Napoléon III est l'auteur d'une Guerre des Gaules de César, 2 vol., Paris 1865.

59 On lira avec intérêt - et profit - le paragraphe consacré par E. Schwartz à l' “ Homère télémachisé » de Fénelon (Dieux et Mortels, École nationale supérieure des BeauxArts, 2004, p. 35-36), notamment pour ce qui concerne la dimension moralisatrice.

60 Il faut ajouter que d'autres œuvres d'Ovide peuvent, mais beaucoup plus rarement, se trouver mobilisées : les Fastes, les Héroïdes, l'Art d'Aimer, voire les Tristes.

61 Certains thèmes ovidiens se retrouvent bien sûr dans la littérature moderne (ex. : Philémon et Baucis chez La Fontaine). 
traductions (Amyot, Ricard, Madame Dacier ...) ${ }^{62}$, notamment pour les premiers temps de Rome (Vie de Numa ou Tite-Live?). Un dernier exemple, qui montre bien avec quelle attention il faut veiller au sujet représenté et à sa contextualisation, est fourni par l'histoire de Philoctète abandonné à Lemnos, dont Ulysse vient ultérieurement reprendre les armes données par Héraclès. Les personnages sont évidemment homériques ; toutefois, quand Ulysse vient, non pas seul, mais accompagné de Néoptolème, la source est le Philoctète de Sophocle ${ }^{63}$.

Dans ce groupe d'inspirateurs “probables» (plus de 800 références et 39 auteurs), le trio Ovide-Homère-Plutarque domine, tandis qu'Apulée et Longus, avec des personnages bien identifiables (Psyché, Daphnis et Chloé64) prennent de l'importance avec un pic dans les années 1861-70, au détriment de Virgile, Suétone et Tacite. Longus bénéficie à compter de 1810 de la révision de la traduction d'Amyot réalisée par Paul-Louis Courier ${ }^{65}$. Les références aux Métamorphoses d'Apulée sont toutefois peut-être surestimées car La Fontaine, on le sait, est l'auteur d'un Les Amours de Psyché et Cupidon. ${ }^{66}$

Ovide apparaît au total comme une référence majeure, avant Homère et Virgile. Chez les historiens, Plutarque l'emporte. Les auteurs de « romans » (Apulée et Longus) sont utilisés au même niveau que les tragiques grecs (environ 10\% des références explicites et « probables »).

Reste la question de l'accès aux sources littéraires et des médiations qui facilitent cet accès ${ }^{67}$, dans un contexte où le niveau de connaissance ou de familiarité avec la source antique pouvait être très variable. Ne négligeons pas l'hypothèse d'une réelle érudition. Néanmoins, pour un Couture qui cite Juvénal ${ }^{68}$, pour

62 Voir J.-L. Quantin, “ Traduire Plutarque d'Amyot à Ricard ”, in Histoire, économie et société, 1988, n. 2, p. 243-259.

63 Ph. Grunchec, Les concours des prix de Rome, avait déjà fait cette observation. Ajoutons qu'une autre version donne Ulysse accompagné de Diomède chez Euripide, mais nous n'avons pas trouvé de tableau reprenant cette version ni au Salon, ni pour les Prix de Rome de Peinture.

64 Avec, pour Longus, le personnage secondaire de Philétas. Voir au Salon de 1870 : Edouard Ponsan, Le récit de Philétas, Longus, livre 2.

65 Les pastorales de Longus ou Daphnis et Chloé, Traduction de J. Amyot revue, corrigée, complétée par Paul-Louis Courier, 1810 (il y aura des rééditions, notamment à la fin de notre période en 1866 et 1878).

66 La Fontaine déclare s'être inspiré d’Apulée, mais “il ne cesse de s'en écarter». Cf. C.L. Badiou-Monferran, " La Fontaine, Les Amours de Psyché et de Cupidon. Commentaire stylistique : l'Assemblée des déesses ", in L'information grammaticale, 73, 1997, p. 24. On est en plein dans l'hypertextualité selon Genette (Palimpsestes, Paris 1982).

67 S. Schvalberg, Le modèle grec, p. 44, “La documentation livresque des artistes ».

68 Juvénal, Satires, VI, 292-293. Encore s'agit-il, pensons-nous, surtout d'un prétexte 
un Ingres grand lecteur d'Homère ${ }^{69}$, ou pour un Gustave Moreau ${ }^{70}$ doté d'une solide formation intellectuelle aux humanités classiques, combien d'artistes ayant peint des Léda, des Narcisse, des Psyché ou des morts de Cléopâtre, pour lesquels le cheminement depuis Ovide, Apulée, ou Plutarque, a suivi des voies très « médiates ».

Les médiations peuvent être picturales ou littéraires. Picturales, elles renvoient à des œuvres de la Renaissance au $\mathbf{x v I I I}^{\mathrm{e}}$ siècle, très célèbres ou moins. Ainsi, par exemple, les auteurs des assez nombreux Diane et Actéon exposés au fil des salons $(1810,1819,1843,1861,1863,1867,1878)$, s'ils puisent à la source ovidienne ${ }^{71}$, le font peut-être directement, mais peuvent le faire aussi de façon médiate, en se référant par exemple au tableau du Titien (1556-1559).

Littéraires, les médiations se déclinent en trois catégories. La première catégorie correspond aux traductions : traductions d'Amyot et de Madame Dacier pour Plutarque ${ }^{72}$; pour Ovide, traduction de Villenave pour les Métamorphoses $(1806)^{73}$ et traductions des Hérö̈des de la Renaissance au xIx $^{\mathrm{e}}$ siècle $^{74}$; traductions desMétamorphoses d'Apulée là encore de la Renaissance au XIx ${ }^{\mathrm{e}}$ siècle ${ }^{75}$; traduction par Paul-Louis Courier du roman de Longus ${ }^{76}$; traduction des Idylles de Théocrite par Firmin Didot ${ }^{77}$; et bien entendu nombreuses traductions d'Homère, dont celle de Leconte de Lisle vers la fin de notre période.

pour Couture à qui un proche avait auparavant fait connaître le festin de Trimalchion (Pétrone, Satyricon) ; voir Callu, art. cit. S. Schvalberg Le modèle grec, p. 246 souligne en contrepoint l'hostilité de Couture aux anecdotes littéraires, “ces prétendues béquilles poétiques ", comme il l'écrit lui-même.

69 N. Schlénoff, Ingres. Ses sources littéraires, PUF, Paris 1956, p. 61 et 236.

70 M. Lutz, La Grèce dans l'imaginaire de Gustave Moreau. Terre des Muses et des Poètes, thèse École des Chartes, 2010 : “ Tout au long de sa carrière, il rêve la Grèce antique à travers ses lectures et un contact direct avec l'art antique, qui le maintiennent à la pointe des découvertes archéologiques ... L'œuvre de Gustave Moreau fait la part belle aux poètes grecs ».

71 Métamorphoses, III, 217s.

72 J.-L. Quantin, Traduire Plutarque.

73 Les Métamorphoses d'Ovide. Traduction nouvelle avec le texte latin, suivie d'une analyse de l'explication des fables, de notes géographiques, historiques, mythologiques et critiques par M. G. T. Villenave; ornée de gravures d'après les dessins de MM. Lebarbier, Monsiau, et Moreau. À Paris, chez les éditeurs, F. Gay, Ch. Guestard, Quatre tomes, 1806.

74 P. Chiron, “ Traduction et "conversion" des épitres héroïdes d'Ovide à la Renaissance », in Anabases, 17, 2013, p. 119-133. Au xix siècle, traduction des Euvres complètes sous la direction de M. Nisard, Paris, J.J. Dubochet et Cie, 1838.

75 Ex. : Georges de la Bouthière, 1553 ; V. Bétolaud, 1835.

76 Il s'agit, comme on l'a déjà signalé, de la traduction d'Amyot revue et complétée par Paul-Louis Courier (1810).

77 Les Idylles de Théocrite suivies de ses inscriptions, traduites en vers français, par Firmin Didot, Paris, Firmin Didot, 1833. 
La deuxième catégorie correspond à des œuvres littéraires originales des XvII et $\mathrm{xvIII}^{\mathrm{e}}$ siècles qui ont soit “ transposé », soit " complété » des œuvres littéraires de l'Antiquité. Du premier cas de figure relèvent par exemple la Phèdre de Racine (Euripide), Les Amours de Psyché et de Cupidon de La Fontaine (Apulée), ou l'Iphigénie en Tauride de Goethe (Euripide) et le poème de Schiller Héro et Léandre (Ovide). Du second cas de figure relèvent par exemple le Télémaque de Fénelon (1699), ou bien encore le Voyage du jeune Anacharsis en Grèce, dans le milieu du quatrième siècle avant l'ère vulgaire (1788) ${ }^{78}$. Ces œuvres, tout comme les traductions contemporaines, ont pu stimuler les inspirations, comme le montrent certaines références explicites.

La troisième catégorie enfin comprend les très nombreux cours, recueils, dictionnaires, encyclopédies, histoires, publiés au XvıII ${ }^{\mathrm{e}}$ siècle et tout au long du $\mathrm{XIX}^{\mathrm{e}}$ siècle dans lesquels nos peintres pouvaient puiser. Nous avons déjà évoqué les manuels d'histoire romaine de Rollin et Crevier. Citons encore : le Dictionnaire abrégé de la Fable pour l'intelligence des Poëtes, des Tableaux \& des Statues, dont les sujets sont tirés de l'Histoire Poëtique ${ }^{79}$ de Chompré, le Dictionnaire abrégé pour l'intelligence des auteurs classiques grecs et latins ${ }^{80}$, le Dictionnaire abrégé des hommes célèbres de l'Antiquité et des Temps modernes ${ }^{81}$, l'Abrégé de la mythologie universelle ou Dictionnaire de la Fable ${ }^{82}$, la Biographie universelle ancienne et moderne (qui comprend une Partie mythologique) ${ }^{83}$, etc. On n'aura garde d'oublier les ouvrages scolaires, tel le Cours de mythologie pour servir à l'intelligence des auteurs classiques grecs et latins de 1829 destiné aux élèves de la classe de sixième ${ }^{84}$.

78 Barthélémy “ récupère » ainsi un personnage d'Hérodote, puis de Lucien. Mais son Voyage est aussi une Périégèse en un sens...

79 Paris, 1727, nombreuses rééditions. E. Schwartz (Dieux et mortels, p. 28) le cite comme le plus utilisé au xvıı̀ è siècle.

80 Yverdon, 1774 [tiré du Grand dictionnaire de M. Sabbathier, Professeur au collège de Châlons-sur-Marne].

81 A.-S. Le Blond, Paris, 1802.

82 Par F. Noël, 1805. L'ouvrage se trouve dans la bibliothèque de Gustave Moreau (M. Lutz, La Grèce dans l'imaginaire).

83 Paris, chez L.-G. Michaud, 1825 (réédition en 1833).

84 Par Alexandre Émile Lefranc, Paris, Charles Gosselin libraire. Exemple éclairant avec, exposé au Salon de 1878, un tableau de Santiago Arcos, Chloris, fille d'Arcture, est enlevée par Borée. Si le Dictionnaire de la Mythologie de P. Grimal ne nous donne pas de clé, le Cours pour la classe de sixième, nous raconte l'histoire (ainsi que certains des ouvrages cités dans notre texte), mais sans en citer la source antique; or, celle-ci se trouve dans l'ouvrage du Pseudo-Plutarque, dont le titre latin courant est De Fluviis, dans le paragraphe consacré au Phase. Il semble a priori raisonnable de penser que ce sont les dictionnaires ou les cours qui ont inspiré Arcos plus que le Pseudo-Plutarque. 


\section{Prix de Rome de Peinture versus Salon : un décalage culturel}

\section{L’Antiquité dans les sujets des Prix de Rome de Peinture}

Notre corpus prend en compte les sujets choisis ainsi que les sujets proposés par le jury. Rappelons toutefois que les données sur les sujets proposés sont lacunaires ${ }^{85}$. Le nombre de sujets proposés en amont est très variable d'année en année, et des sujets proposés se retrouvent assez souvent d'une année sur l'autre, jusqu'à ce qu'ils finissent par être choisis ou bien soient abandonnés : nous avons donc un phénomène de récurrence relativement important.

Les sujets sont en pratique soit antiques, soit bibliques. Les quelques sujets “ autres » ne se trouvent que dans les sujets proposés et sont très peu nombreux ${ }^{86}$.

Les sujets antiques dominent parmi les sujets choisis pour toute la période 1791-1880, avec un peu plus de 70\%, un peu moins parmi les sujets proposés (60\%). On observe par ailleurs le rythme ternaire que nous connaissons bien désormais avec une chute de la part des sujets antiques choisis pendant les trois décennies de 1831 à 1860. Il semble en revanche que la part des sujets antiques proposés tende à diminuer sur l'ensemble de la période, mais les lacunes de la documentation incitent à la prudence (Tableau 12, Graphique 17).

\begin{tabular}{|l|r|r|r|r|r|r|r|r|r|r|}
\hline & $\begin{array}{c}1791- \\
1799\end{array}$ & $\begin{array}{r}1800- \\
1810\end{array}$ & $\begin{array}{r}1811- \\
\mathbf{1 8 2 0}\end{array}$ & $\begin{array}{c}\mathbf{1 8 2 1 -} \\
\mathbf{1 8 3 0}\end{array}$ & $\begin{array}{c}\mathbf{1 8 3 1 -} \\
\mathbf{1 8 4 0}\end{array}$ & $\begin{array}{c}\mathbf{1 8 4 1 -} \\
\mathbf{1 8 5 0}\end{array}$ & $\begin{array}{c}\mathbf{1 8 5 1 -} \\
\mathbf{1 8 6 0}\end{array}$ & $\begin{array}{c}\mathbf{1 8 6 1 -} \\
\mathbf{1 8 7 0}\end{array}$ & $\begin{array}{c}\mathbf{1 8 7 1 -} \\
\mathbf{1 8 8 0}\end{array}$ & Total \\
\hline $\begin{array}{l}\text { Sujets antiques } \\
\text { choisis }\end{array}$ & 4 & 10 & 9 & 8 & 4 & 6 & 4 & 9 & 7 & 61 \\
\hline $\begin{array}{l}\text { Sujets bibliques } \\
\text { choisis }\end{array}$ & 1 & 1 & 1 & 2 & 6 & 4 & 6 & 1 & 3 & 25 \\
\hline Total sujets & 5 & 11 & 10 & 10 & 10 & 10 & 10 & 10 & 10 & 86 \\
\hline $\begin{array}{l}\text { \% sujets antiques } \\
\text { total }\end{array}$ & $80 \%$ & $90,91 \%$ & $90 \%$ & $80 \%$ & $40 \%$ & $60 \%$ & $40 \%$ & $90 \%$ & $70 \%$ & $70,93 \%$ \\
\hline $\begin{array}{l}\text { Sujets antiques } \\
\text { proposés }\end{array}$ & 4 & 20 & 68 & 50 & 41 & 51 & 37 & 15 & 21 & 307 \\
\hline $\begin{array}{l}\text { Sujets bibliques } \\
\text { proposés }\end{array}$ & 1 & 7 & 12 & 25 & 42 & 26 & 49 & 15 & 25 & 202 \\
\hline $\begin{array}{l}\text { Autres sujets } \\
\text { proposés }\end{array}$ & 0 & 0 & 3 & 2 & 2 & 0 & 0 & 0 & 0 & 7 \\
\hline $\begin{array}{l}\text { Total sujets } \\
\text { proposés }\end{array}$ & 5 & 27 & 83 & 77 & 85 & 77 & 86 & 30 & 46 & 516 \\
\hline $\begin{array}{l}\text { \% sujets antiques } \\
\text { proposés / total }\end{array}$ & $80,00 \%$ & $74,07 \%$ & $81,93 \%$ & $64,94 \%$ & $48,24 \%$ & $66,23 \%$ & $43,02 \%$ & $50,00 \%$ & $45,65 \%$ & $59,50 \%$ \\
\hline
\end{tabular}

Tableau 12. Prix de Rome de Peinture -

Sujets choisis et sujets proposés par décennie 1791-1880

85 Voir plus haut: Sources et méthodologie, p. 40.

86 Ils sont tirés du Tasse et de Dante. 


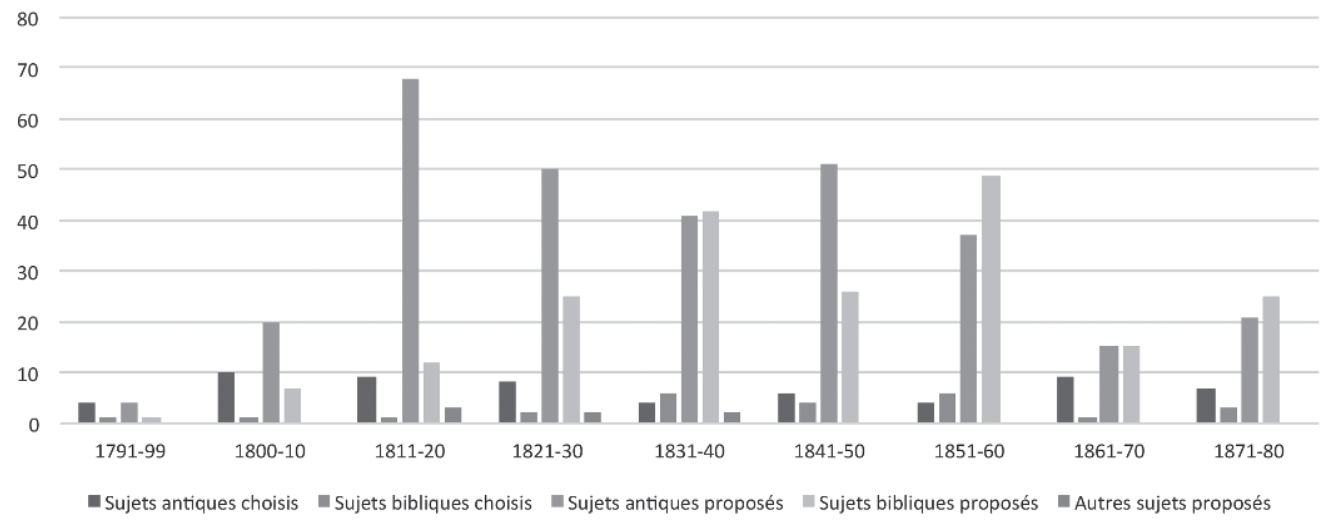

Graphique 17. Prix de Rome de Peinture - sujets choisis et sujets proposés par décennie (valeurs absolues) 1791-1880

Les comparaisons que l'on peut faire avec le Salon sont assez claires. Pour les Prix de Rome de Peinture, l’Antiquité reste bien présente - et prégnante, en particulier dans les sujets choisis, alors qu'au Salon, elle devient résiduelle en pourcentage, même si le flux de peintures à sujets antiques se maintient en valeur absolue et si le nombre de peintres « antiquisants » reste encore non négligeable dans les deux dernières décennies de notre période ${ }^{87}$. Cela dit, pour les Prix de Rome de Peinture comme au Salon, la Monarchie de Juillet - et, très nettement, sa première décennie - constitue à n’en pas douter une période de rupture où se manifeste un singulier recul des thèmes antiques. Il y a là un parallélisme que l'on pourrait difficilement attribuer au hasard.

\section{Dieux, héros et mortels dans les sujets}

Les dieux sont très rares ${ }^{88}$ dans les sujets choisis. Point de « petit peuple mythologique ». Les héros et les personnages mythologiques et littéraires constituent un peu plus de la moitié des personnages représentés, suivis des personnages historiques - dont trois auteurs, Homère, l'aède aveugle de Chénier, Sophocle (devant l'Aréopage) et Platon (au cap Sounion). Les personnages historiques devancent les personnages mythologiques et littéraires seulement pendant les décennies 1800-10 et 1851-60.

87 S. SchVAlberg, Le modèle grec, p. 72-73.

88 On rencontre seulement Jupiter et Mercure dans le Prix de Rome de 1818, dans le contexte ovidien du récit de Philémon et Baucis. 
Tandis que les personnages mythologiques et littéraires grecs (homériques en premier lieu, puis tragiques) surpassent très largement les romains (virgiliens) pratiquement à huit contre un, les personnages historiques grecs ne dominent les romains que dans un rapport 55/45 (Tableau 13).

\begin{tabular}{|l|r|r|r|r|r|r|r|r|r|r|}
\hline Sujets proposés & $\begin{array}{r}1791- \\
1799\end{array}$ & $\begin{array}{r}\mathbf{1 8 0 0 -} \\
\mathbf{1 8 1 0}\end{array}$ & $\begin{array}{c}\mathbf{1 8 1 1 -} \\
\mathbf{1 8 2 0}\end{array}$ & $\begin{array}{c}\mathbf{1 8 2 1 -} \\
\mathbf{1 8 3 0}\end{array}$ & $\begin{array}{c}\mathbf{1 8 3 1} \\
\mathbf{1 8 4 0}\end{array}$ & $\begin{array}{c}\mathbf{1 8 4 1 -} \\
\mathbf{1 8 5 0}\end{array}$ & $\begin{array}{c}\mathbf{1 8 5 1} \\
\mathbf{1 8 6 0}\end{array}$ & $\begin{array}{c}\mathbf{1 8 6 1 -} \\
\mathbf{1 8 7 0}\end{array}$ & $\begin{array}{l}\mathbf{1 8 7 1 -} \\
\mathbf{1 8 8 0}\end{array}$ & Total \\
\hline $\begin{array}{l}\text { Héros, pers. } \\
\text { myth. et litt. }\end{array}$ & 0 & 7 & 79 & 45 & 22 & 20 & 22 & 10 & 16 & 221 \\
\hline dont grecs & 0 & 6 & 70 & 39 & 16 & 20 & 19 & 10 & 16 & 196 \\
\hline dont romains & 0 & 1 & 9 & 6 & 6 & 0 & 3 & 0 & 0 & 25 \\
\hline $\begin{array}{l}\text { Personnages } \\
\text { historiques }\end{array}$ & 5 & 23 & 29 & 30 & 37 & 39 & 26 & 10 & 14 & 213 \\
\hline dont grecs & 0 & 8 & 21 & 22 & 23 & 17 & 11 & 7 & 2 & 111 \\
\hline dont romains & 5 & 11 & 8 & 8 & 10 & 18 & 14 & 3 & 12 & 89 \\
\hline dont orientaux & 0 & 4 & 0 & 0 & 4 & 4 & 1 & 0 & 0 & 13 \\
\hline $\begin{array}{l}\text { dont auteurs } \\
\text { (grecs) }\end{array}$ & 0 & 2 & & 2 & 4 & 4 & 2 & 1 & 0 & 15 \\
\hline Total & $\mathbf{5}$ & $\mathbf{3 0}$ & $\mathbf{1 0 8}$ & $\mathbf{7 5}$ & $\mathbf{5 9}$ & $\mathbf{5 9}$ & $\mathbf{4 8}$ & $\mathbf{2 0}$ & $\mathbf{3 0}$ & $\mathbf{4 3 4}$ \\
\hline
\end{tabular}

Tableau 13. Héros et personnages mythologiques et littéraires, personnages historiques dans les sujets proposés pour le Prix de Rome de Peinture 1791-1880

Le paysage intellectuel ainsi dessiné se situe hors de l'Olympe, comme hors du répertoire ovidien. Il est dominé par l'univers homérique (l'Iliade aux trois quarts environ), accessoirement par le monde virgilien, et par l'histoire, tant grecque (celle du v viècle avant J.-C. à 60\%) que romaine (aux trois quarts des débuts de la République à sa chute).

\section{Les sources littéraires des sujets}

Les sources sont directement identifiables pour les sujets choisis grâce aux procès-verbaux des séances extraordinaires : la référence littéraire est très souvent fournie, et la scène à représenter décrite de façon détaillée, voire très détaillée, ce qui, en l'absence de référence littéraire, permet en principe de retrouver la source. Il en va tout autrement pour l'éventail des sujets proposés en amont par les différents membres du jury, pour lesquels nous nous retrouvons dans le cas de figure des peintures des Salons privées de référence littéraire explicite. Toutefois, il faut souligner que la récurrence de certains sujets - qui finissent par être retenus comme « sujet définitif »-permet parfois de nous éclairer.

Plutarque et Homère viennent largement en tête des 11 auteurs explicitement mobilisés (hors Chénier et Crevier). Loin derrière viennent Ovide, Sophocle, TiteLive et Virgile (Tableau 14). 


\begin{tabular}{|c|c|c|c|c|c|c|c|c|c|c|c|}
\hline Auteurs & \begin{tabular}{c|}
$1791-$ \\
1799 \\
\end{tabular} & $\begin{array}{c}1800- \\
1810 \\
\end{array}$ & $\begin{array}{c}1811- \\
1820\end{array}$ & $\begin{array}{c}1821- \\
1830\end{array}$ & $\begin{array}{c}1831- \\
1840\end{array}$ & $\begin{array}{c}1841- \\
1850\end{array}$ & $\begin{array}{c}1851- \\
1860\end{array}$ & $\begin{array}{c}1861- \\
1870 \\
\end{array}$ & $\begin{array}{c}1871- \\
1880\end{array}$ & Total & $\%$ \\
\hline Chénier 89 & & 1 & & & & & & & & 1 & $2 \%$ \\
\hline Crevier 90 & & 1 & & & & & & & & 1 & $2 \%$ \\
\hline Euripide & & & & 1 & & & & & & 1 & $2 \%$ \\
\hline Homère & & 3 & 3 & & 1 & & & 1 & 2 & 10 & $22 \%$ \\
\hline Ovide & & 1 & 1 & 1 & & & & & & 3 & $7 \%$ \\
\hline Pausanias & & & 2 & & & & & & & 2 & $4 \%$ \\
\hline Plutarque & 3 & 3 & 1 & 2 & & 1 & 2 & 1 & 2 & 15 & $33 \%$ \\
\hline Sophocle & & & & 1 & & 1 & & 1 & & 3 & $7 \%$ \\
\hline Suétone & & & & & & & & & 1 & 1 & $2 \%$ \\
\hline Tacite & & & & & & & & 1 & & 1 & $2 \%$ \\
\hline Thucydide & & & 1 & & & & & & & 1 & $2 \%$ \\
\hline Tite-Live & 1 & 1 & & & & & & & 1 & 3 & $7 \%$ \\
\hline Virgile & & 1 & 1 & & & & & 1 & & 3 & $7 \%$ \\
\hline Total (13) & 4 & 11 & 9 & 5 & 1 & 2 & 2 & 5 & 6 & 45 & $100 \%$ \\
\hline
\end{tabular}

Tableau 14. Prix de Rome de Peinture - Auteurs ayant fait l'objet d'une référence explicite (sujets choisis) 1791-1880

Les références « probables » concernant les sujets proposés (186) confirment la large domination de Plutarque et d'Homère.

Les artistes concourant pour le Prix de Rome de Peinture sont souvent présents au Salon. Une étude future pourra permettre d'établir quelles relations pourraient exister entre tel ou tel maître (Cogniet, Couture, Gleyre, par exemple) et les thèmes choisis par ses élèves. Toutefois, force est de souligner le décalage très significatif entre les sujets choisis et proposés pour les Prix de Rome et ceux choisis par les peintres exposant au Salon (dont les peintures ont fait l'objet d'une sélection, ce qui introduit le “biais» du jury). Alors que les sujets des Prix de Rome sont dominés par Plutarque pour l'histoire, lequel est suivi d'Homère pour la mythologie et la fiction, les sujets du Salon privilégient, comme nous l'avons vu, le répertoire ovidien, suivi par les références à l'univers homérique et au couple Apulée-Longus. Ovide est singulièrement peu présent dans les sujets des Prix de Rome, tandis qu'Apulée et Longus en sont pratiquement absents.

Le Prix de Rome de Peinture reste ainsi dominé par les sujets considérés comme “ nobles », issus des Vies de Plutarque et du monde de l'épopée homérique - l'Iliade plus que l'Odyssée ${ }^{11}$ - alors que le Salon tend à privilégier la mythologie comme

89 Idylles, L’Aveugle, nombreuses éditions, dont 1819 (Euvres complètes, texte établi par Henri de Latouche).

90 Ch. Rollin et J.B.L. Crevier, Histoire romaine, Paris, 1746.

91 Les références à l'Iliade représentent 70\% environ du total des références homériques. 
fiction romanesque (chez Ovide, Apulée, Longus) et l'histoire sous un angle plus anecdotique ${ }^{92}$, en faisant une large place, à côté des héros de la Grèce antique et de la République romaine (les favoris du Prix de Rome ${ }^{93}$ ), à des scènes et à des personnages de la “décadence» (ainsi à travers Suétone et Tacite: Agrippine, Néron et Locuste, Tibère à Capri, Caligula, etc.), à commencer par le célèbre Les Romains de la décadence de Thomas Couture (Salon de 1847) ${ }^{94}$.

\section{Conclusion}

À chaque période, et sans surprise, la représentation de l'Antiquité a reflété la culture des élites et la pensée politique des dirigeants, et comme le dit E. Schwartz, “tous les sujets antiques sont propres à juger les événements du moment présent ${ }^{95}$. Les quelque dix années de la Révolution ont été une période d'usage dense de l'histoire ancienne, avec la peinture néo-classique - et au-delà de la peinture ; les Romains et les Grecs, mais les Romains plus que les Grecs, ont été convoqués pour donner image et sens aux vertus républicaines et à une culture “égalitaire ». Le Premier Empire commence à réévaluer les apports antiques, rééquilibrant Grecs et Romains (Alexandre et Auguste), tout en manifestant les dernières traces de l'Historia Magistra. Louis-Philippe veut combler les fractures entre Français et crée le Musée d'Histoire de France, comme une vaste fresque racontant les hauts faits de l'histoire nationale de Clovis à lui-même et à ses fils, et réoriente ainsi, directement et indirectement, le marché de l'art, tandis que le « goût bourgeois » porte aux scènes de genre, aux portraits et aux paysages. Le Second

Les références à l'Odyssée sont très majoritairement concentrées sur le retour d'Ulysse à Ithaque (scènes de reconnaissance d'Ulysse, les prétendants).

92 S. Schvalberg, Le modèle grec, p. 208, évoque le "parti-pris satirique " de Gérôme (“L'humeur plaisante de Gérôme et le sérieux de l'École des Beaux-Arts »).

93 Les personnages de la Grèce classique sont une écrasante majorité (avec une nette préférence pour Épaminondas, suivi du couple Cimon-Miltiade). À Rome, les personnages des débuts de Rome et de la “belle " période de la République sont majoritaires (Coriolan, Cincinnatus...), suivis de personnages de la période de la guerre civile, à la fin de la République, et du Haut-Empire. Les sujets traitant de César ne se trouvent que sous le Second Empire.

94 J.-P. Callu, "Les Romains de la Décadence" : regards du xix ${ }^{\mathrm{e}}$ siècle français (18091874) ", in Comptes rendus de l'Académie des Inscriptions et Belles-Lettres, $141^{\mathrm{e}}$ année, N. 4, 1997, p. 1143-1156.

95 Catalogue de l'exposition D’Antigone à Marianne. Rêves et réalités de la République. E. Schwartz D’Antigone à Marianne, cite à ce propos le Prix de Rome de Peinture de 1830, Méléagre reprenant les armes à la sollicitation de son épouse, œuvre d'Émile Signol, dans laquelle figure un minuscule drapeau tricolore (p. 48-49). 
Empire sonne l'heure d'un certain retour à l'antique, à double face. Érudite d'un côté, avec le souci de l'archéologie (non sans arrière-pensées politiques), plus tard le Parnasse avec les traductions de Leconte de l'Isle. Anecdotique (voire satirique) et érotique de l'autre, avec une débauche de déesses, nymphes et bacchantes.

Ainsi, la « noble » Antiquité de la Révolution et de l'Empire, celle qui persiste envers et contre tout à l'Académie avec les Prix de Rome, devient, après l'Antiquité romantique de la Restauration, une Antiquité qui s'inscrit dans une érotisation de la mythologie, privilégiant le répertoire ovidien et celui des fictions d'Apulée et Longus.

Notre objectif était ici, rappelons-le, une analyse quantitative, fondée sur des données aussi fiables que possible et «stabilisées ». De ce fait même, bien des questions restent en suspens que ce travail n'a fait qu'effleurer, depuis le rôle des maîtres de l'École des Beaux-Arts dans le maintien ou l'effacement des thèmes antiques au Salon (notamment à travers les jurys de sélection) jusqu'à celui de la typologie respective des scènes représentées - et non plus seulement des personnages - dans les deux périodes où les moyennes par Salon des peintures à thèmes antiques sont les plus élevées, la Restauration et le Second Empire.

Mireille Lacave Allemand

Historienne de l'art

mireille.lacave@sfr.fr

\section{Michel Lacave}

Professeur agrégé

des Facultés de Droit

(Droit romain et Histoire du Droit)

michel.lacave@gmail.com 